\title{
Petrographical and petrophysical properties of sandstones: statistical analysis as an approach to predict material behaviour and construction suitability
}

\author{
H. Stück $\cdot$ R. Koch $\cdot$ S. Siegesmund
}

Received: 10 June 2012/ Accepted: 12 September 2012/Published online: 25 October 2012

(C) The Author(s) 2012. This article is published with open access at Springerlink.com

\begin{abstract}
Most studies dealing with material properties of sandstones are based on a small data set. The present study utilizes petrographical and petrophysical data from 22 selected sandstones and $\sim 300$ sandstones from the literature to estimate/predict the material and weathering behaviour of characteristic sandstones. Composition and fabric properties were determined from detailed thin section analyses. Statistical methods applied consist of data distributions with whisker plots and linear regression with confidence regions for the petrophysical and weathering properties. To identify similarities between individual sandstones and to define groups of specific sandstone types, principal component and cluster analyses were applied. The results confirm an interaction between the composition, depositional environment, stratigraphic association and diagenesis, which leads to a particular material behaviour of sandstones. Three different types of pore radii distributions are observed, whereby each is derived from different pore space modifications during diagenesis and is associated with specific sandstone types: (1) bimodal with a maximum in capillary and micropores, (2) unimodal unequal with a maximum in smaller capillary pores and (3) unimodal equable with a maximum in larger capillary pores. Each distribution shows specific dependencies to water absorption, salt loading and hygric dilatation. The strength-porosity relationship shows dependence on the content of unstable lithic fragments, grain contact and type
\end{abstract}

H. Stück $(\bowtie) \cdot S$. Siegesmund

Geoscience Centre of the University Göttingen,

Goldschmidtstr.3, 37077 Göttingen, Germany

e-mail: hstueck@gwdg.de

R. Koch

University of Erlangen, GeoCentre Northern Bavaria,

Löwenichstr.28, 91054 Erlangen, Germany of pore radii distribution, cementation and degree of alteration. Sandstones showing a maximum of capillary pores and micropores (bimodal) exhibit a distinct hygric dilatation and low salt resistance. These sandstones are highly immature sublitharenites-litharenites, characterized by altered unstable rock fragments, which show pointedelongated grain contacts, and some pseudomatrix. Quartz arenites and sublitharenites-litharenites which are strongly compacted and cemented, show unimodal unequal pore radii distributions, low porosity, high strength and a high salt resistance. The presence of swellable clay minerals in sublitharenites-litharenites leads to a medium to high hygric dilatation, whereas quartz arenites show little hygric dilatation. Sandstones with unimodal equal pore radii distribution mostly belong to weakly compacted and cemented mature quartz arenites. These are characterized by high water absorption and high porosity, low to medium strength and a low salt resistance. The data compiled in this study are used to create a sandstone quality catalogue. Since material properties are dependent on many different parameters of influence, the transition between different lithotypes is fluent.

Keywords Sandstones - Pore space - Prediction · Weathering behavior Compressive strength

\section{Introduction}

Due to their great availability, sandstones are commonly used as a natural stone for buildings, monuments and sculptures. The wide variety of different applications increases the need to understand their characteristic material properties. Complex sedimentary processes are involved in the origin of sandstones. These include the 
source material, transport processes, the depositional environment and diagenesis. Characterizing and predicting the material properties of sandstone requires detailed investigations of sedimentological, petrographical and petrophysical parameters (Koch and Sobott 2008; Morales Demarco et al. 2007; Rüdrich et al. 2010). Thereby, the characteristics of the pore space such as porosity, permeability and pore geometry are most important for the weathering behaviour of porous sandstones (cf. Fitzner 1988; Fitzner and Snethlage 1982; Putnis et al. 1995; Putnis and Mauthe 2000; Rüdrich et al. 2010). In this context, a linear correlation between porosity and compressive strength and flexural strength as well as water balance and storage properties has been reported by Rüdrich et al. (2010).

However, most of these studies are based on a small data set of samples and parameters. Therefore, general statements covering a wide stratigraphic range and different sandstone types of varying depositional environments and diagenetic development cannot be made. A statistical analysis of the parameters such as grain size, compositional and textural maturity, cementation and fabric, which essentially control the material properties of sandstones, is lacking.

Therefore, the aim of the present study is to establish criteria and systems, which aid in predicting the weathering behaviour of various sandstone types. This is based on a statistical analysis of a large data set that includes most of the parameters generally used when analysing the quality of a sandstone. The study is based on a large amount of petrographical and petrophysical data collected from 300 sandstones described in the literature. Twenty-two of the total samples analysed represent important sandstones used in Germany. These sandstones were investigated in detail by petrographic analysis, determining the fabric characteristics, measuring the petrophysical properties and combining all these data using statistical analyses.

When using data from the literature, it has to be taken into account that the data might not be complete in regard to petrographical analyses and petrophysical measurements. Commonly, just single samples are taken when analysing a quarry, and thus the samples collected may not represent the wide variety of facies types present. For sandstones frequently used, this might be less problematic because only certain qualities are generally regarded. Further possible sources of error may be caused by different approaches during sampling, preparation of samples, different methods and the apparatus used for analysis (Rac and Chernyshev 1970). Data found on the Internet or from company brochures need to be used with caution, since the information may only reflect the optimum quality but not the natural variations of quality in a quarry. Therefore, the data utilized in the present study originates from scientific non-commercial sources, which deal with material testing and/or research.
Sedimentary processes as a key to understanding material behaviour of sandstone

The path from unconsolidated sediment to lithified sandstone suitable for construction is controlled by complex sedimentary and diagenetic processes (Tucker 2001). The mineralogical composition of sandstone (compositional maturity) and the textural maturity are dependent on sedimentological parameters (e.g. transport, depositional environment), which contribute to the petrophysical properties, and to a certain degree the weathering behaviour. Diagenesis begins immediately after/with deposition and includes processes of compaction, pressure solution, recrystallization, dissolution, replacement/alteration, clay mineral and feldspar authigenesis as well as cementation by varying mineral phases (Burley et al. 1985; Morad et al. 2000; Tucker 2001; Koch and Sobott 2008). Diagenetic realms include eo-, meso- and telogenetic processes (Choquette and Pray 1970) acting from shallow to deep burial conditions depending on the chemistry of pore water present. The development of pore space geometry through time together with the alteration of grain contacts are parameters of special importance. Cements and compaction lead to the reduction of the primary intergranular pore space. Eogenetic cements also shelter the rock against later compaction during deeper burial (Worden and Morad 2000). Some cement is dissolved by processes forming a late-stage secondary porosity.

Clay material as a primary matrix, pseudomatrix and/or later infiltration into open pore spaces is a significant problem of sandstones with regard to their weathering stability, since they considerably influence porosity and permeability (Houseknecht and Pittman 1992). Neoformation, transformation and alteration of different clay minerals under varying conditions (temperature, pressure and water access) define clay minerals as a special parameter in sandstones that requires careful analysis when characterizing the material behaviour of a sandstone.

\section{Methods}

To support this investigation, a large data set was taken from the literature (Fig. 2; Table 1) dealing with the petrographical and petrophysical analysis of sandstones (Bartelsen 2008; Seidel 2004; Chitsazian 1985; David 2006; Fitzner 1970; Grimm 1990; Holzwarth 1996; Kirsten 2009; Mosch and Siegesmund 2007). Basic parameters such as porosity, density, water uptake and strength are included for the sandstones from all over the world, partially originating from the natural stone industry and from the data collected in detailed studies dealing with German sandstones. 
Petrographical and petrophysical properties of 22 selected sandstones representative for sandstone types from various geological periods were analysed. Standard parameters were measured according to the DIN standards (German Industry Norm) for material testing.

Material parameters measured according to international standards (e.g. DIN) were used without any further adaptation. In contrast, the petrographic data had to be adapted in some cases for the development of a uniform classification. Data quality for grain size and sorting is different depending upon whether detailed analyses are made or just estimations are given. Furthermore, not for every rock each petrophysical property could be found in literature. Therefore, the number of samples shown in the diagrams (see Chap. 3.2) can vary.

\section{Petrographical analysis}

Thin section analysis was carried out on the 22 representative samples. Classification was done by point counting (Van der Plas and Tobi 1965) and using the classification system of McBride (1963), which allows integrating the weathering sensibility of sandstones (Hayes 1984). Füchtbauer (1988) counts chert and quartzite fragments as a group of rock fragments, whereas in the classification of McBride both are interpreted as stable grains and thus belong to the quartz group. Therefore, in the classification system of McBride, two weathering-sensitive end members and a weathering-resistant one are differentiated.

In the classifications of Gilbert (1954) and Pettijohn (1975), the matrix is generally considered, which is useful for rocks with a matrix content $>15 \%$. Thus, (grey-) wackes are seldom used for construction because of their unsuitable weathering properties and are therefore not considered in the present study. According to this, data from the classification of sandstones investigated by David (2006), Grimm (1990) and Fitzner (1970) were transferred to McBride's classification.

Fabric parameters determined by thin section analysis are grain contacts, sorting (Pettijohn et al. 1987), roundness as well as textural and compositional maturity. Grain size analyses determined by thin section do not completely correspond to grain sizes measured by sieving as discussed by Müller (1964).

The visible intergranular porosity and amount of cements were estimated to acquire information about the compaction history. The data were plotted in the "Houseknecht diagram" (Houseknecht 1992). Besides the classification of maturity by McBride (1963), the varying degrees of alteration, reflecting increasing alteration of unstable components such as feldspar and lithoclasts, were subdivided into the classes (1) high, (2) moderate, (3) little and (4) no degree of alteration.
X-ray diffractometry (XRD) and X-ray fluorescence were applied to determine the bulk and clay mineral composition of selected sandstone samples. The cation exchange capacity for crushed whole rock samples was analysed using $\mathrm{Cu}(\mathrm{II})$-triethylene tetramine. X-ray diffraction was done for grain size fractions of $<2 \mu \mathrm{m}$. Grain size fractions $<2 \mu \mathrm{m}$ were collected from fractions $<63 \mu \mathrm{m}$ by differential settling in distilled water, i.e. by using the Atterberg method following Stoke's law. The collected sample is prepared by placing them onto ceramic plates, air dried and coated with ethylene glycol. The samples were measured at $2 \Theta=2^{\circ}-35^{\circ}$ with $0.02^{\circ}$ and $3 \mathrm{~s}$ per step.

\section{Petrophysical analyses}

Petrophysical parameters including data on the pore space, strength as well as water transport and storage were determined according to the DIN standards. Porosity, matrix density and bulk density were measured in accordance with DIN 52102. The dry mass was determined on samples after 2 days of preconditioning at $20{ }^{\circ} \mathrm{C}$ and $15 \%$ relative humidity. The hydrostatic and the saturated mass were detected after water saturation under vacuum.

Pore radii distribution was accomplished on cylindrical samples (10 $\mathrm{mm}$ in diameter, ca. $20 \mathrm{~mm}$ in length) using mercury porosimetry (van Brakel et al. 1981; porosimeter 2000 Carlo Erba). The pressures used up to 2 kbar allow the evaluation of pore radii of about $0.005 \mu \mathrm{m}$.

The capillary water absorption was measured according to DIN 52103 with an under-floor balance, parallel and perpendicular to the bedding. The measurements were performed on sample cubes $(65 \times 65 \times 65 \mathrm{~mm})$, which were dipped to $5 \mathrm{~mm}$ in water. The weight increase was digitally measured every $20 \mathrm{~s}$. The capillary water absorption can be expressed by the water absorption coefficient ( $w$ value), which represents the absorbed water amount dependent on area and time $\left(\mathrm{kg} /\left(\mathrm{m}^{2} * \sqrt{\mathrm{h}}\right)\right)$. The saturation degree was calculated from the water uptake under atmospheric and vacuum conditions on the same samples.

Water vapour diffusion was measured with the wet-cup method (DIN 52615) on samples $40 \mathrm{~mm}$ in diameter and $10 \mathrm{~mm}$ in length. Samples were exposed at $30^{\circ} \mathrm{C}$ and a relative humidity of $50 \%$. The weight was measured four times every $24 \mathrm{~h}$. The sorption/desorption was measured in a climate chamber during a stepwise increase of moisture between 15 and $95 \%$ relative humidity. A stepwise decrease was performed until the humidity reached the initial level of $15 \%$. Every humidity level was held for $24 \mathrm{~h}$. After equilibration, the mass of the samples was weighed.

The tensile strength was measured using the Brazil test according to DIN 22024. The uniaxial compressive 
Fig. 1 a Whisker plot showing mean, lower and upper extreme data as well as outliers of univariate data, b possible distribution of data inside a regression analysis with regression coefficient, and c example for regression analyses between water uptake and porosity with confidence region of $80 \%$ probability range, illustrated by the blue ellipsoid. d Diagram of the multivariate method showing the principal component analyses: rock properties present the variables and are illustrated by blue axes. Arrows pointing in the same direction are dependent on each other; arrows pointing in the opposite direction show negative correlation, whereas arrows that perpendicular to each other are independent of each other. For further explanation, see text

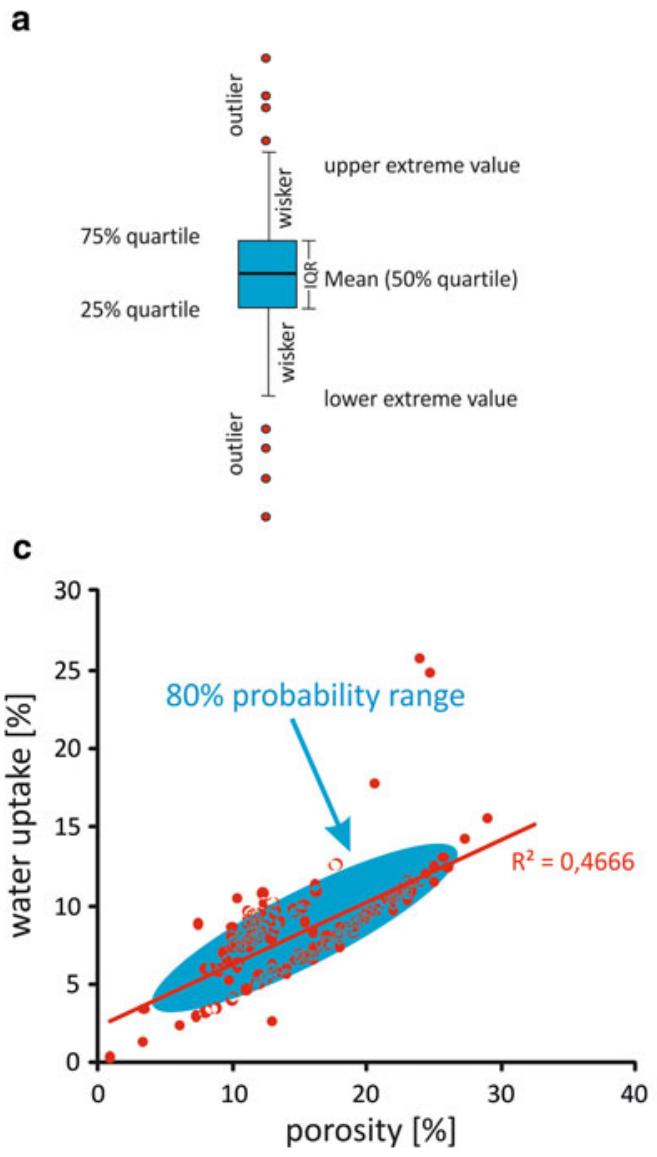

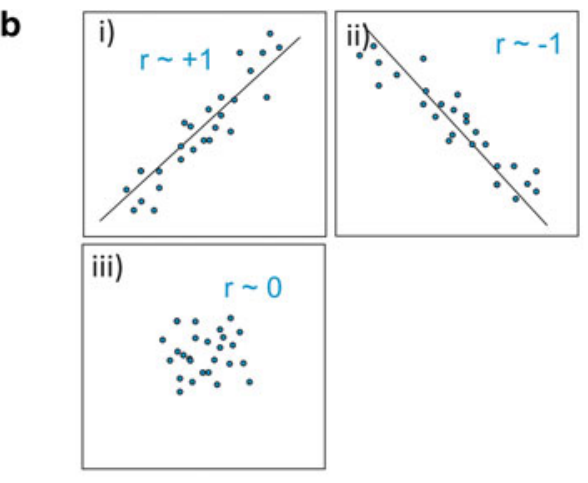

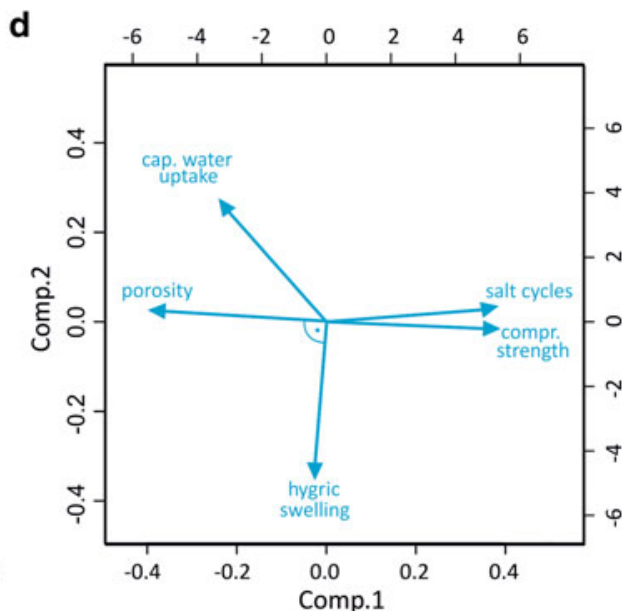

strength was measured on cylindrical samples $(50 \mathrm{~mm} \times$ $50 \mathrm{~mm}$ in size) with coplanar end faces (accuracy of $0.1 \%$ ) in the dry and water-saturated state. The load was applied to the end faces of the specimen with a strain rate of $1,000 \mathrm{~N} / \mathrm{s}$ until failure.

\section{Analysis of weathering properties}

The hygric dilatation was determined in dependence of the water saturation. In general, the expansion is determined with an incremental displacement transducer (resolution about $5 \mu \mathrm{m}$ ) on samples of $10 \mathrm{~cm}$ in length and $15 \mathrm{~mm}$ in diameter. A preconditioning of the specimens was achieved by drying in a climatic chamber at $20{ }^{\circ} \mathrm{C}$ and $15 \%$ relative humidity.

Salt splitting tests were accomplished following DIN 52111 with a $10 \%$ solution of sodium sulphate. The sample cubes ( $65 \mathrm{~mm}$ edge) were soaked for $6 \mathrm{~h}$ in solution and afterwards dried for $12 \mathrm{~h}$ in a drying chamber at $60{ }^{\circ} \mathrm{C}$. After this, they were weighed and photographically documented. The experiment was ended after reaching 100 cycles or after a loss of $40 \%$ of the original material. The salt weathering resistance of sandstones analysed as well as data from David (2006) were grouped as follows:
Group $\mathrm{A}=$ no material loss until the 100th cycle

Group B $=50 \%$ material loss until 30-40 cycles

Group C $=$ lose $50 \%$ of their weight after

the 15 th cycle.

Statistical methods (univariate, bivariate and multivariate)

Statistical analyses can be divided into univariate, bivariate and multivariate methods and each method considers a different dimensional problem. The statistical treatment of the data set was performed with the open software " $R$ GUI".

To analyse the distribution of one rock property (univariate), box-whisker plots were used as shown in Fig. 1a). The data are illustrated in a "five-point-summary", which includes the median, two quartiles, extreme values and outliers. The box represents the area where $50 \%$ of the data are included and which is limited by the upper (75\% quartile) and lower median ( $25 \%$ quartile). The length of the box expresses the so-called interquartile ranges (IQR) and is also a degree of scattering. The median divides the total diagram into two parts, and its position allows an evaluation concerning the skewness of the data 
distribution. According to Tukey (1977), the length of the whiskers is limited by 1.5 times the interquartile range. All values outside of the whiskers are characterized as outliers. In the present study, this method was used for all data of individual properties as well as for recognizing interrelationships between the composition and age of the sandstones.

To investigate the relationship between two properties, essentially a two-dimensional problem, a linear regression was performed (bivariate method). The values of two properties are represented in correlation point diagrams. The correlation coefficient expresses the relationship of two features (Bravais-Pearson coefficient). The coefficient can vary between +1 and -1 ; thereby, a positive value describes a linear relationship with a positive increase (Fig. 1b i) and a negative value a relationship with a negative increase (Fig. $1 \mathrm{~b}$ ii). Correlations with no linear relationships, e.g. a cloud arrangement of points, are shown in Fig. 1b iii. Furthermore, within regression analyses confidence regions with $80 \%$ probability range are determined under the assumption that basic properties like porosity, density or strength show normal distribution. Exemplarily, the relationship between water absorption and porosity (Fig. 1c) is illustrated, where $80 \%$ probability range is presented by a small, elongated ellipse.

To combine the relationships of all the measured parameters, which are important for characterizing the material behaviour of sandstone, multivariate methods of principal component and cluster analyses were performed. Principal component analyses try to reduce a multidimensional problem. The hypothetical variables are constructed, which minimize the entire sum of squared deviations of a best-fit straight line. The calculated components try to describe the wide difference/variance between the properties and the samples. Since the data of sandstones are based on different physical units, they differ in dimension and the influence of properties with high variance can overlay the variance of other properties, which would lead to an incorrect calculation of components. Therefore, principal component analyses were accomplished after previous standardization. The pre-treatment includes a calculation of the $q-q$-norm and a correlation matrix (Dohrmann and Kühn 2009). Where necessary, data were logarithmized. Principal component analyses are illustrated with biplots, which include information on variables (rock properties) and samples in one diagram (Fig. 1d). The position of variables to each other is expressed by the loadings, which are calculated by the variances of the variables. They are illustrated as arrows, and the position to each other expresses the particular relationship (Fig. 1d). Arrows pointing in the same direction have a positive relationship to each other. In contrast, arrows pointing in opposite directions exhibit a negative relationship to each other. If there is no relationship between two properties, arrows stand perpendicular to each other. Samples are depicted as points and the coordinates within the diagram in this multidimensional system are calculated via scores, which are based on the loadings of the components.

Cluster analyses were done for identifying groups of similar sandstones, based on all known properties. The principle of cluster analysis follows two steps: (1) determination of similarities between the objects and their properties, and (2) determination of the cluster number. The similarity is determined via proximity degree and is calculated with the Euclidian distance matrix. For illustration, a so-called dendrogram was used.

\section{Results}

The petrographic analysis includes all the data from this study as well as from the literature. Both reveal a great variety of sandstone properties based on data from different stratigraphic levels.

General remarks on sandstones from different sources and stratigraphic position

Most of the data originate from Middle European sandstones (Fig. 2), which were predominantly deposited in a cratonic basin. For a discussion of the petrography and material properties, the stratigraphic position must also be taken into account as documented by Grimm (1990), Chitsazian (1985), David (2006), Fitzner (1970), Holzwarth (1996), Kirsten (2009), Seidel (2004), Bartelsen (2008) and Koch and Sobott (2008).

The occurrence of different sandstones in the stratigraphic column is grouped according to their importance and regional distribution. In Germany, the most important sandstones occur in the Lower and Upper Triassic (Fig. 2). Ten sandstone quarries were evaluated and analysed in the present study. Lower Triassic sandstones are quarried at the Weser River, in the Hessische Senke, in Spessart, Odenwald, in the Pfälzerwald Mountains and in the Black Forest. Upper Triassic sandstones are predominantly mined in the Thuringian Basin, at the River Main, and between the Black Forest and the Swabian Alb. Sandstones, Cretaceous in age, are also significant (six quarries evaluated), which are concentrated in the "Münsterländer Becken", the Hildesheim Bay in northeastern Germany and at the Elbe River in eastern Germany. Carboniferous and Permian sandstones are rare due to their low occurrence. They are mined in the north of the Harz Mountains, at the Thuringian-Bavarian border, Hunsrück and in the north of the Rhenish Slate Mountains. 
Fig. 2 Map of quarries and sandstones investigated. Outcrops of deposits from Carboniferous, Permian, Lower and Upper Triassic as well as Cretaceous are illustrated. Sample locations and literature sources for different sandstones are indicated. Numbers represent the sandstones investigated in this study (Table 1)

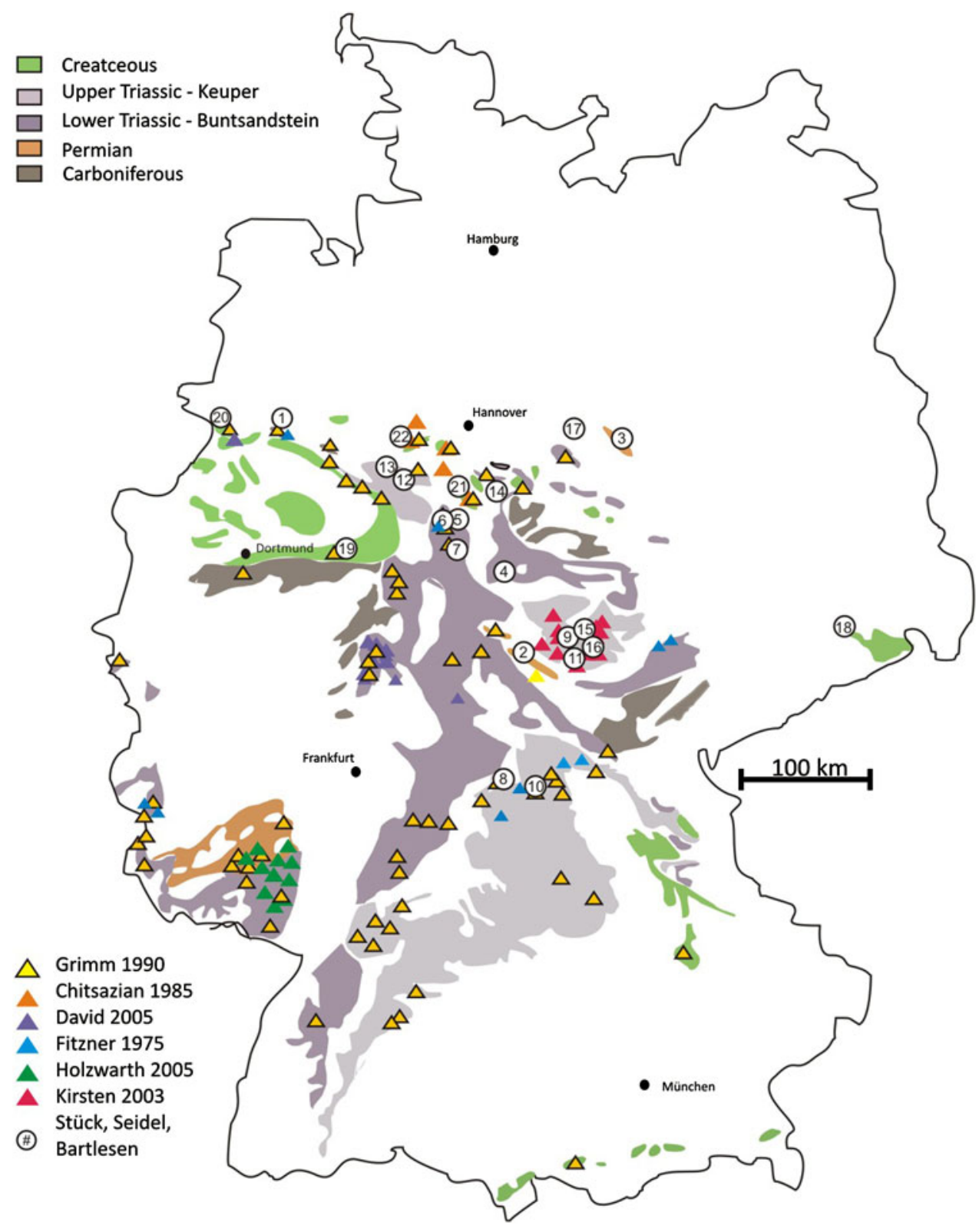

The sediments of the geologic ages considered are the result of changing depositional environments through time, associated with transgressive and regressive marine influence. The depositional environments of the sandstones range from pure clastic terrigeneous (fluviatile, aeolian) to marine facies, which are also reflected in their characteristic sedimentary structures. Most of the sandstones can be classified as quartzites, lithic subarkoses, sublitharenites as well as minor litharenites and subarkoses. The distribution of sandstone types is characteristic for epicontinental basins such as the German Basin. Therefore, arkoses are represented only in very minor amounts. Short descriptions of different depositional facies are given, which change in each sedimentary basin through time.
Carboniferous are the oldest sandstones analysed in the present study (e.g. the Ibbenbüren sandstone). The sediments were deposited in flood plains and alluvial fans to the north of the Variscan orogeny (Katzung 1975; Plein 1993). They consist of feldspathic litharenites and sublitharenites and partially contain conglomeratic layers and coal particles. The Ibbenbüren sandstone is characterized by strong compaction and cementation and also a clayey matrix.

During the Permian, the German Basin was filled with shallow marine to terrestrial mixed carbonate/siliciclastic sediments (Aigner and Bachmann 1992). The Rotliegend sandstones crop out in southern Germany, Thuringia and at the Flechtinger mountain range, where terrestrial deposits 


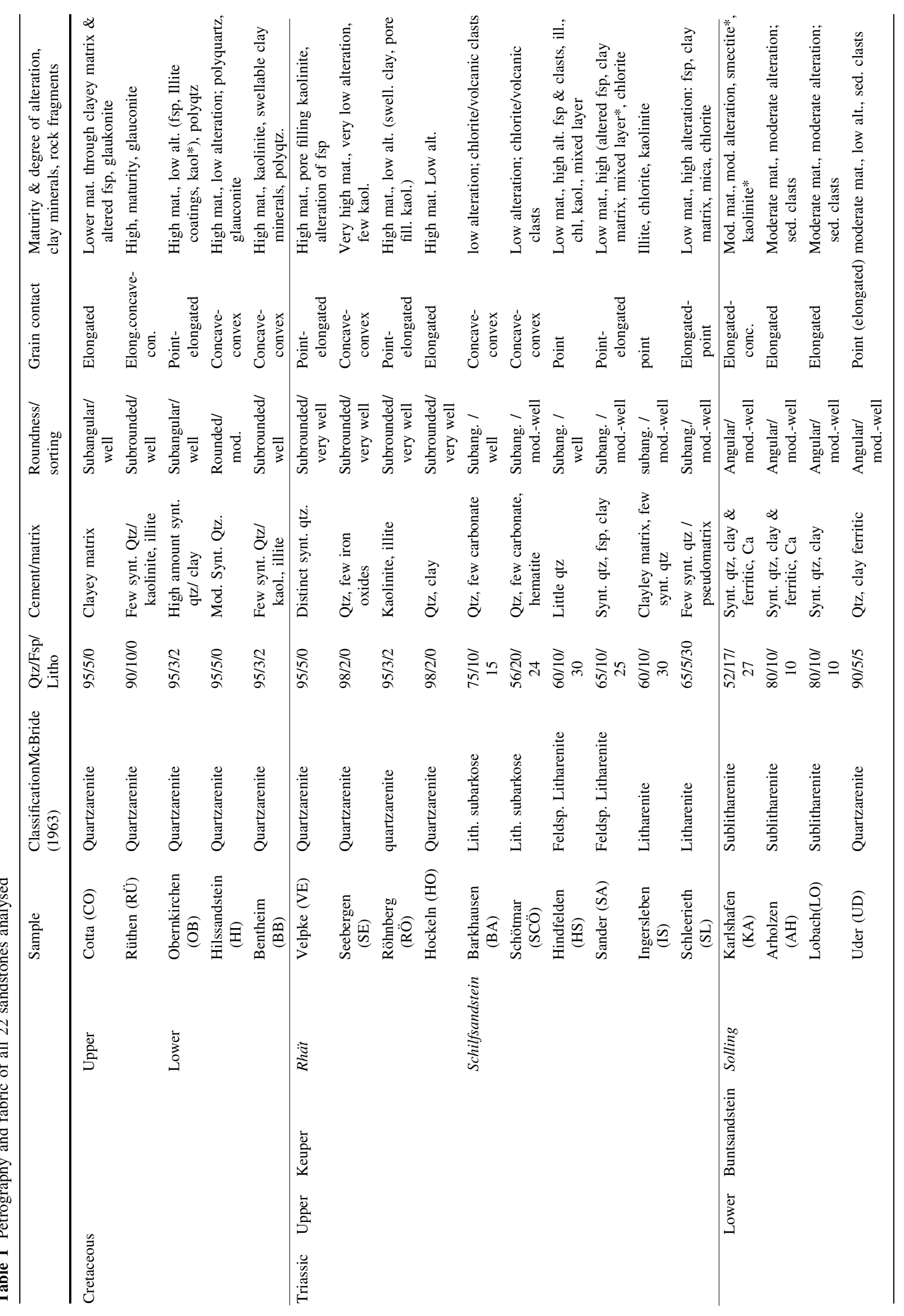


formed lithic subarkoses and sublitharenites occur. According to Strack and Stapf (1980), they are fluviatile deposits from flood plains and channel facies.

Triassic sandstones of the Buntsandstein are terrigeneous deposits of predominantly sublitharenitic composition. Sandstones of the Middle Buntsandstein commonly show quartz arenitic to sublitharenitic composition. The depositional environment of the Bunter sediments changes markedly through time. In the Lower Bunter playa facies, braided river systems formed at the margins (Paul 1982), which are characterized by fining upward cycles. The sandstones of the Middle Buntsandstein are characterized by prograding fluvial sandstones with a common channel facies (Karlshafen, Arholzen, Uder and Lobach). Sandstones of the Upper Bunter are seldom used as building stones because they mainly consist of clayey and silty deposits.

Sandstones of Upper Triassic (Keuper) age are characterized by marked changes of the depositional environment through time. They also document a great variability in their physical properties. Considerable natural stone deposits belong to the Lettenkohlenkeuper, Schilfsandstein and Rhät Formations (Lower, Middle and Upper Keuper). Sandstones deposited during the Schilfsandstein and Lettenkohlenkeuper are mainly litharenites and sublitharenites, commonly with highly altered unstable rock fragments. Sandstones of the Lettenkohlenkeuper (Ingersleben and Schleerieth sandstones) were deposited in a brackish marine delta environment with local moors. Local coal layers also occur with the same name designation (Beutler and Schubert 1987; Paul et al. 2008). Sediments of the Schilfsandstein (Sander, Hindfelden, Schötmarer and Barkhausen sandstones) were deposited in a wide delta facies covering a flat shelf. They formed meandering delta arms filled by up to $50 \mathrm{~m}$ of fine sand (Wurster 1964). Rhät sandstones are characterized by quartz arenites (the Velpke, Hockeln, Seebergen and Röhnberg sandstones). They were deposited under changing depositional environments from marine to lacustrine-terrestrial. The sediments are predominantly composed of alternating fine sands and mudstones (Seidel 2003). Very coarse channel fills also occur (Koch et al. 2003; Sobott and Koch 2009) in the Franconian Rhät deposits.

Cretaceous sandstones (Cotta, Rüthen, Hilssandstein, Obernkirchen and Bad Bentheim) were deposited in the coastal rim area formed by a transgression from the north. They mainly consist of quartz arenites, in which the marine environment is partially well documented by the occurrence of glauconite (greensands).

Petrographical analyses-composition and fabric

Compositionally, the sandstones investigated can generally be defined as quartz arenites, sublitharenites, litharenites 

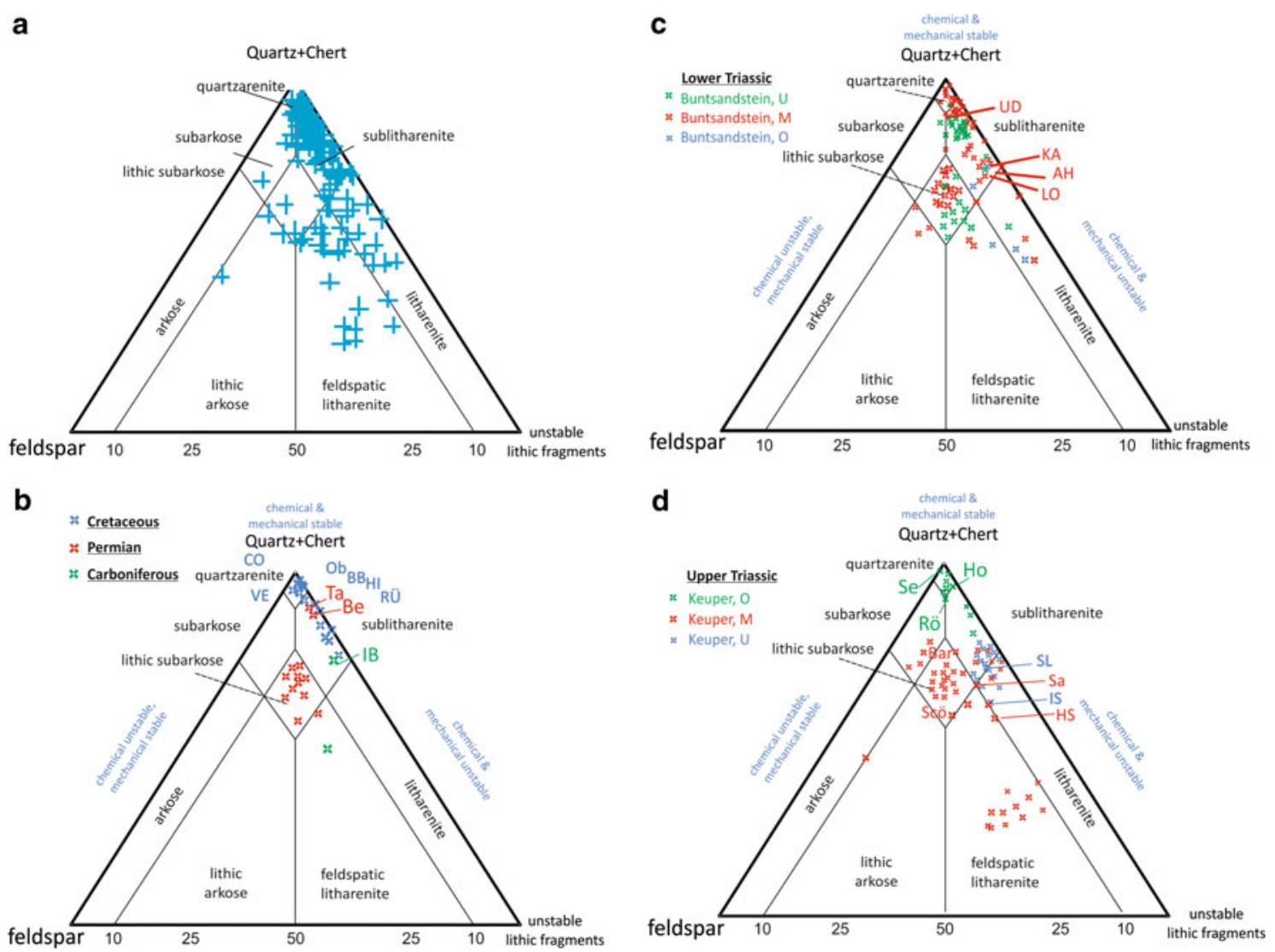

Fig. 3 Classification of sandstones investigated after McBride (1963) and Hayes (1984). b IB Ibbenbüren sandstone, $T a$ Tambach sandstone, $B e$ Bebertal sandstone, $V e$ Velpke sandstone, $C O$ Cotta sandstone, $R \ddot{U}$ Rüthen sandstone, $B B$ Bad Bentheim sandstone, $H i$ Hilssandstein, $O b$ Obernkirchen sandstone; c $L O$ Lobach sandstone,

and lithic subarkoses according to McBride (1963, Fig. 3). Arkoses and lithic arkoses are very rare in this data set. The 22 sandstones which were analysed in detail comprise a wide range of different sandstone types and are representative for the entire dataset compiled from the literature ( $\sim 300$ samples) in terms of composition, depositional settings and age.

The Ibbenbüren sandstone (Fig. 3; Table 1) of Carboniferous age shows a sublitharenitic composition and is less mature due to its clayey matrix, subangular-subrounded grain shape and well to moderate sorting. The grain contact is predominantly sutured but also concave-convex (Fig. 5a) and visible pore spaces are only moderately recognizable. Cementation occurs as syntaxial quartz overgrowths, whereby the original grain shape is marked by a thin rim of impurities. The Permian Tambach and Bebertal sandstones are both characterized by a sublitharenitic composition. The Bebertal aeolian sandstone only shows moderate sorting (Figs. 4a, 6) with a bimodal grain size, whereby the larger grains are rounded and the smaller

grains rather subrounded. Grain contacts are mostly elongated-concave-convex. Syntaxial quartz overgrowths (Fig. 5a, c) and calcite occur as cement. Locally, the grains are surrounded by early infiltrated clay minerals (illite). Furthermore, X-ray diffraction indicates smectite as the clay mineral found in these sandstones. Cation exchange capacity $(C E C)$ for the whole rock fraction amounts to $1.0 \mathrm{meq} / 100 \mathrm{mg}$ (Bartelsen 2008). The Tambach sandstone is characterized by well sorting and subrounded-subangular grain shapes, concave-convex grain contacts and very well-pronounced syntaxial quartz overgrowths. Furthermore, calcite occurs as a pore-filling cement and feldspar as a grain overgrowth. In addition, detrital grains are surrounded by finely dispersed iron oxides. Partially altered lithoclasts show replacement by chlorite, which was also determined by XRD analyses. The cation exchange capacity is with $1.1 \mathrm{meq} / 100 \mathrm{mg}$ marginally higher than for the Bebertal sandstone (Bartelsen 2008).

The fluviatile Uder, Lobach, Arholzen and Karlshafen sandstones belong to the Lower Triassic of Buntsandstein 
Fig. 4 Representative sandstone types: a Aeolian sandstone (dune deposit; Rotliegend, Bebertal sandstone) revealing a bimodal grain size distribution (x-pol.).

b Sublitharenite with quartzitic and calcareous cementation as well as a haematitic overprinting, which is characteristic for fluviatile sandstones belonging to the Lower Triassic (Karlshafen sandstone; x-pol.). c Highly immature sublitharenitelitharenite with altered lithoclasts, feldspars as well as pseudomatrix (Hindfelden sandstone; II-pol.). d Quartz arenite (Upper Triassic/Rät, Seebergen) showing clean grain contacts, which allows pressure solution leading to concaveconvex to sutured grain contacts (x-pol.). e Quartz arenite with early infiltration of illite forming clay boundaries between grains (Röhnberg sandstone; $\mathrm{x}$-pol.). f Marine sandstone with glauconite grains (Cretaceous, Rüthen; $\mathrm{x}$-pol.)
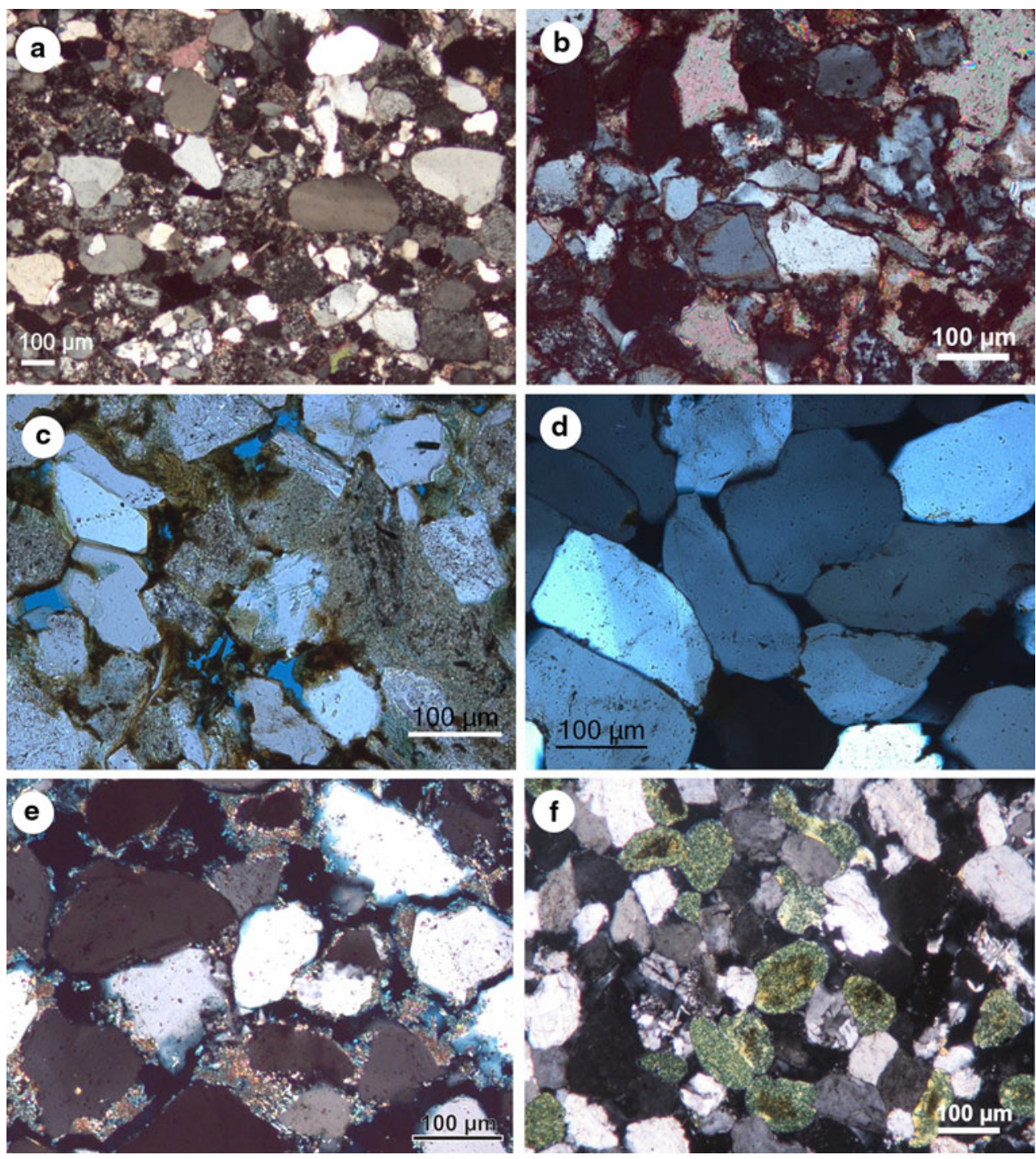

(Table 1). They are sublitharenites in composition with the exception of the Uder sandstone, which is defined as a quartz arenite. While the samples of Lobach, Arholzen and Karlshafen (Weser sandstones) all show distinct alteration of feldspars and lithoclasts, the Uder sandstone shows only little alteration. The three Wesersandstones are characterized by a subangular grain shape, predominantly concaveconvex grain contact, syntaxial quartz overgrowth, calcite cement, locally feldspar cement and often a haematite overprinting of the grain surfaces (Fig. 4b). However, the amount of cement and also the degree of compaction varies. Most of the (quartz-) cementation occurs in the Karlshafen sandstone, followed by Arholzen and finally Lobach. Furthermore, the Karlshafen sandstone shows the strongest compaction. The grains of the Uder sandstone are subrounded, grain contacts pointed-elongated and little stabilizing cement is present; only a clay matrix is recognizable. This sandstone shows little compaction since the grain contacts are predominantly pointed. The sorting and grain size of the Bunter sandstones exhibits distinct variations, whereas the Lobach, Arholzen and Karlshafen sandstones (Wesersandstones) show a moderate to well sorting. The Uder sandstone (Thuringia) is well sorted (Fig. 6). Weser sandstones can be classified as fine sand, whereas the Karlshafen sandstone even shows a fine-silty grain size. The Uder sandstone exhibits a fine-medium grain size. In general, the Uder sandstone is compositionally and texturally more mature than the distinct immature Weser sandstones. The cation exchange capacity for the Karlshafen sandstone equals 2.0, and XRD analyses indicate the presence of chlorite, smectite and kaolinite in the clay fractions $<2 \mu \mathrm{m}$ (Bartelsen 2008).

Both the Schleerieth and Ingersleben sandstones belong to the Lower Keuper (Table 1). They are characterized by a litharenitic composition. The Schleerieth sandstone exhibits little syntaxial quartz overgrowths, a clayey matrix, 

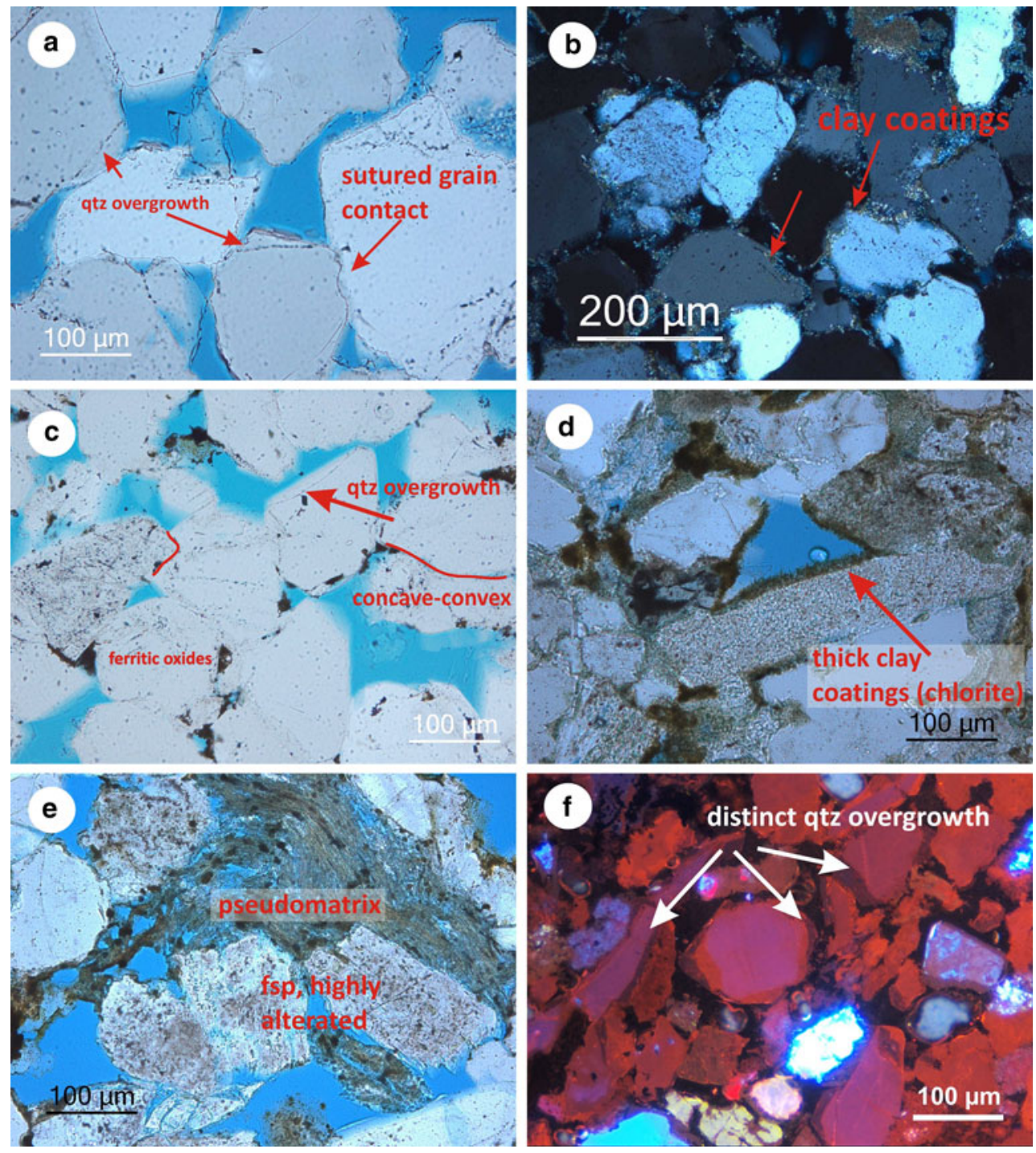

Fig. 5 Characteristic features for grain contacts and cementation. a Syntaxial quartz overgrowth as well as sutured point contact between quartz grains (II-pol.). b Clay coatings of needle-shaped illite lining the pores (x-pol.). c Quartz overgrowth, concave-convex grain contact as well as dark brown ferrous oxides present as rims and

interparticle fillings (II-pol.). d Distinct clay coatings of chlorite at altered grain surfaces (II-pol.). e Squeezed pseudomatrix between altered detrital grains (II-pol.) and $\mathbf{f}$ distinct quartz overgrowths under cathodoluminescence

predominantly point-elongated grain contacts and subrounded grains. Feldspar grains are sericitized and the mainly volcanogenic rock fragments are distinctly altered. Chloritization of volcanogenic rock fragments is also observable. The grain size is coarse silty to fine sandy and the sorting well developed (Fig. 6). XRD analyses show chlorite and illite within the sandstone and its CEC amounts to $2.1 \mathrm{meq} / 100 \mathrm{~g}$ (Bartelsen 2008). Thus, this rock can be defined as very immature sandstone. The Ingersleben sandstone can also be defined as highly immature and is characterized by little compaction and cementation; however, the rock shows a distinct visible pore space. The volcanogenic rock fragments present are highly altered to chlorite and the feldspars show alteration

by sericitization. Often, loose fragments of pseudomatrix between the few stable grains can be observed, and rarely a grain contact between stable components is visible. Locally, relicts of feldspar cement are recognizable, which are also now replaced. The grain contact is mainly pointed or elongated and the grain shape subangular and locally angular. Furthermore, at grain surfaces, chlorite and porelining illite are observable. XRD analyses indicate the presence of chlorite, kaolinite and illite (Fig. 7) and its CEC amounts to $1.4 \mathrm{meq} / 100 \mathrm{~g}$.

Sandstones of the Middle Keuper (Table 1) are predominantly compositionally immature, since the Sander and Hindfelden sandstones are feldspathic litharenites and the Barkhausen and Schötmar sandstones lithic subarkoses. 
a

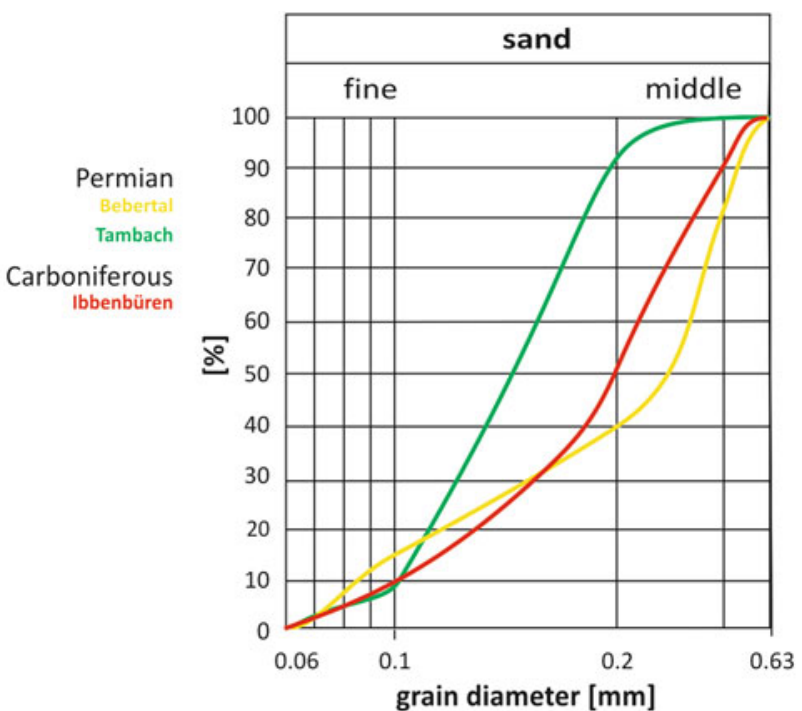

b

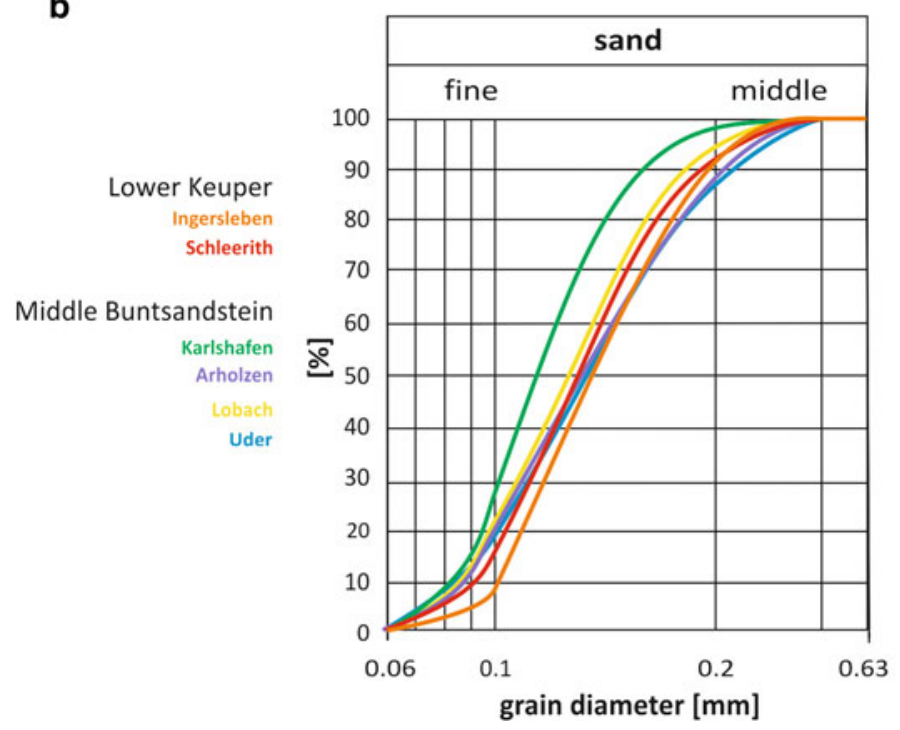

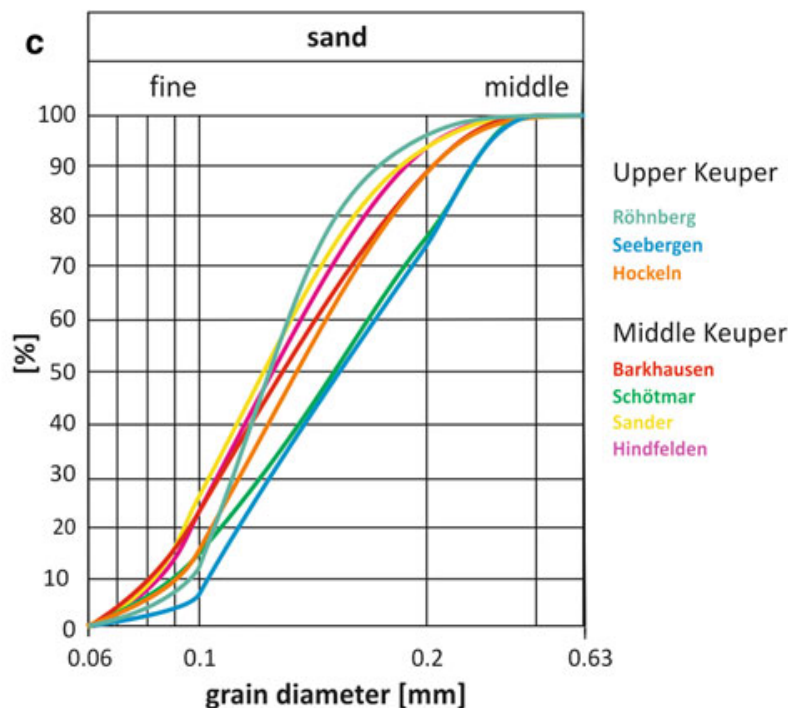

d

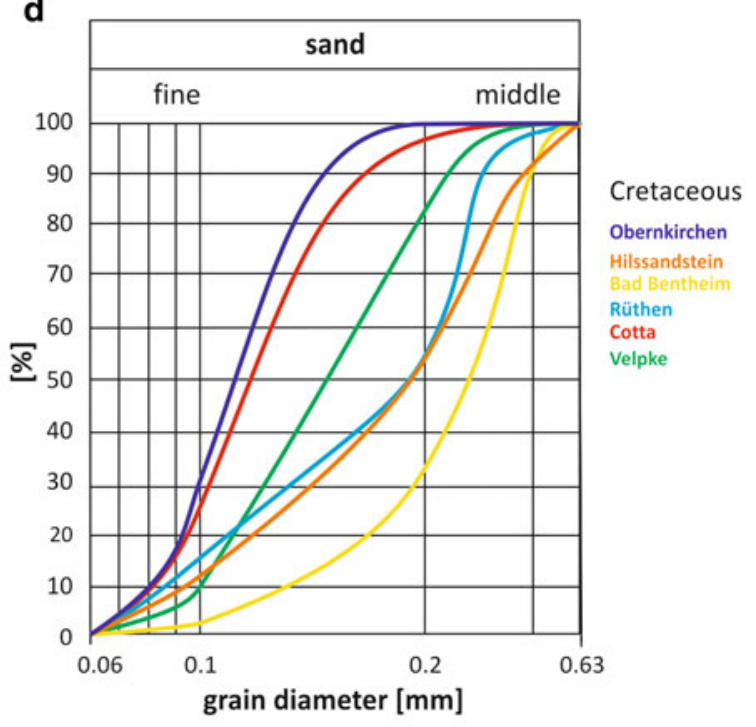

Fig. 6 Sorting of sandstones investigated: a Permian and Carboniferous sandstones, b Buntsandstein and Lower Keuper, c Upper Keuper and d Cretaceous. For sample abbreviations, see Table 1

The Barkhausen, Schötmar and Sander sandstones contain quartz cement, locally feldspar cement and a clayey matrix, whereas the Hindfelden sandstone shows very little quartz cement and a distinct pseudomatrix (Figs. 4c, 5e). The grain surfaces of the Barkhausen, Schötmar and Sander sandstones are overprinted with haematite, while the grain surfaces of the Hindfelden sandstone are overprinted by thick clay-chlorite rims (Fig. 5d). Alteration of feldspar and unstable rock fragments are distinctly developed in the latter sample and rarely a grain contact between stable quartz grains can be observed. Instead of this, quartz grains commonly are floating in the pseudomatrix. In contrast to the Barkhausen and Schötmar sandstones that show concave-convex grain contacts, the Sander sandstone exhibits elongated grain contacts. All Middle Keuper sandstones exhibit a well to moderate sorting and subrounded-subangular grain shape. The grain size of the Barkhausen sandstone is about $100 \mu \mathrm{m}$, the Schötmar sandstone ranges $100-200 \mu \mathrm{m}$, the Hindfelden standstone shows sizes of $80-100 \mu \mathrm{m}$ and the sandstone Sander has a size of around $175 \mu \mathrm{m}$. XRD analyses show a large chlorite and illite content and a small amount of kaolinite in the Hindfelden sandstone (Fig. 7), where its CEC amounts to $4.6 \mathrm{meq} /$ $100 \mathrm{~g}$. The CEC amounts to Sander sandstone $3.4 \mathrm{meq} / 100 \mathrm{~g}$ and swellable mixed layer minerals and kaolinite are detected by XRD analyses.

Seebergen, Röhnberg, Hockeln and Velpke sandstones of the Upper Keuper (Rhät) are all quartz arenites in composition, well to very well sorted, rounded to subrounded and classified as fine, mature sands. They can be 


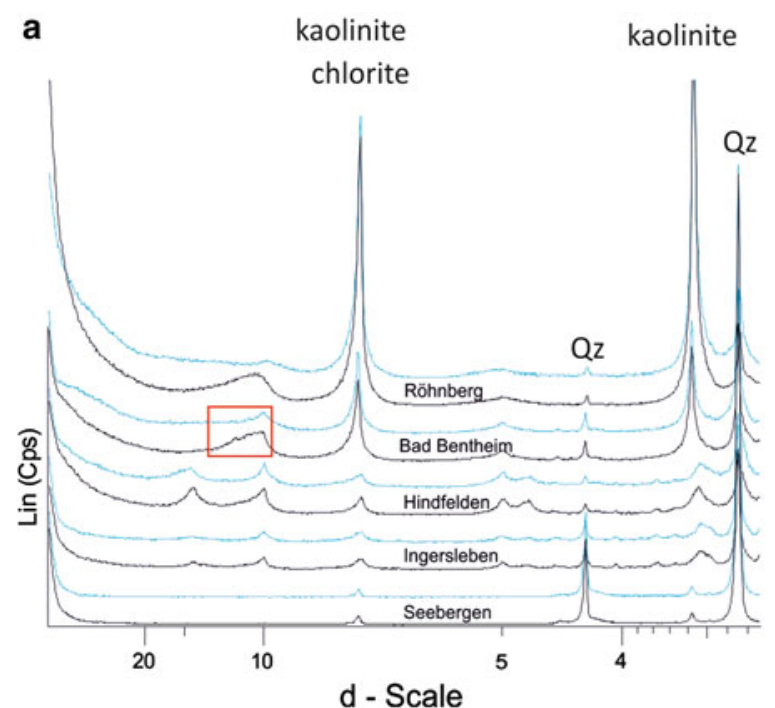

Fig. 7 Mineral content of clay fractions (textural preparates) from the Seebergen, Ingersleben, Hindfelden, Bad Bentheim and Röhnberg sandstones measured at textural specimen. Blue line/red: ethylene

\section{b}

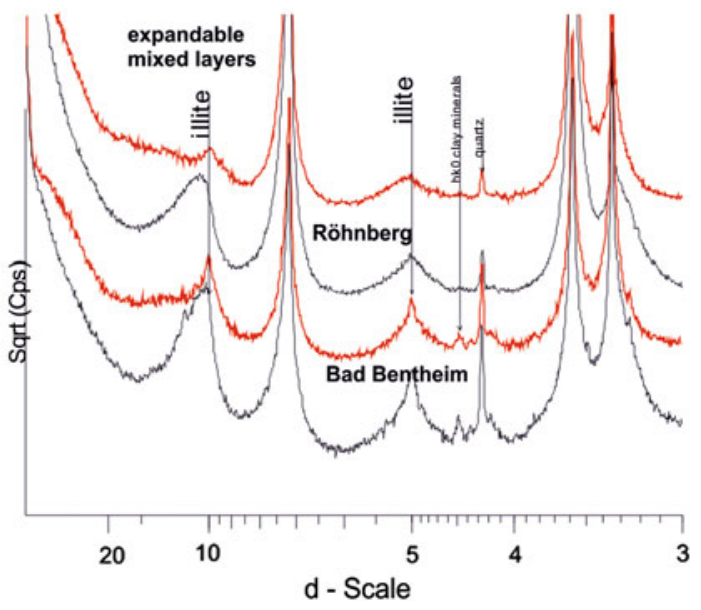

glycolate; black line: air dried. Red rectangle marks the area with the presence of swellable clay minerals e.g. in sandstone Bad Bentheim

Rüthen, Cotta and Hilssandstein sandstones glauconite grains are present (Fig. 4f). After Tucker (2001), sandstone Rüthen has been defined as hybrid sandstone, since here the glauconite occurs to a significant proportion. The few feldspars that occur are only slightly altered by sericitization. With the exception of the Obernkirchen sandstone, whose grains are subangular, the sandstones are subrounded to round. Sandstone Obernkirchen also shows very high amount of quartz cementation, whereas at the other sandstones syntaxial quartz cementation is much lower. In addition, the Cotta sandstone contains a clayey matrix and distinct altered feldspars and therefore is more immature. Rüthen, Bad Bentheim and Obernkirchen sandstones exhibit pore-lining illite and pore-filling kaolinite (Fig. 5b). The grain contact of the Bad Bentheim sandstone is generally pointed, but also concave-convex contact occurs (Fig. 5a). In contrast, the Rüthen and Obernkirchen sandstones mainly show concave-convex grain contacts, and the Cotta and Hilssandstein sandstones predominantly reveal elongated to concave-convex grain contacts. Lowest grain sizes are found in the Obernkirchen sandstone with an average of around $80 \mu \mathrm{m}$, whereas the largest occur in the Bad Bentheim sandstone with an average of around $250 \mu \mathrm{m}$. The sorting of these sandstones is well pronounced. Results from the XRD analyses confirm the presence of high kaolinite contents and swellable clay minerals in the Bad Bentheim sandstone, but the CEC only shows a very low value of $0.1 \mathrm{meq} / 100 \mathrm{~g}$. Furthermore, the sqrt illustration overemphasises the very low intensities of illite (Fig. 7b). In the Bad Bentheim sandstone, illite occurs as mixed phase along with swellable clay minerals. talline quartz grains often occur and in the case of the 


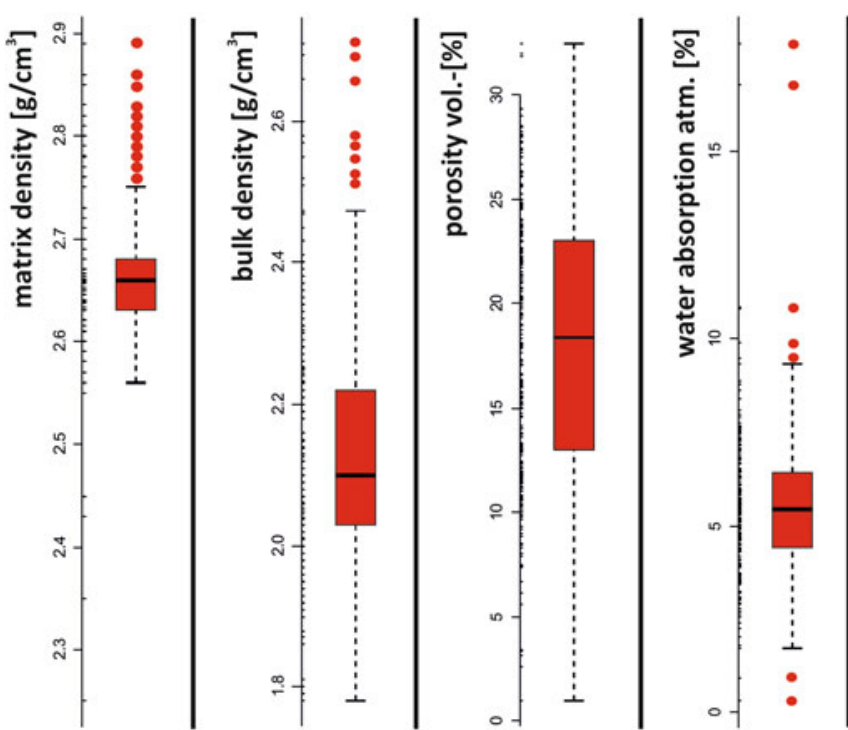

Fig. 8 Whisker plots of petrophysical properties from: matrix density, bulk density and effective porosity $[n=305$; Chitsazian (1985), David (2006), Grimm (1990), Holzwarth (1996), Kirsten (2009), Massallam (1973), Mosch and Siegesmund (2007) and own samples], water uptake under atmospheric and vacuum conditions, capillary water uptake $[n=214$; David (2006), Grimm (1990),

Petrophysical parameters and weathering behaviour

\section{Univariate and bivariate distribution}

Whisker plots document the distribution of all samples of one rock property (Fig. 8). Most of the data exhibit a symmetrical distribution, with the exception of the coefficient of water absorption and the compressive strength.

The mean and the median of the matrix density is $2.66 \mathrm{~g} / \mathrm{cm}^{3}$ (third quartile $2.64 \mathrm{~g} / \mathrm{cm}^{3}$ respectively $2.68 \mathrm{~g} /$ $\mathrm{cm}^{3}$ ), a value that corresponds to the high amount of quartz and feldspar. Deviations from these data are caused by the presence of non-quartzitic rock fragments and by the occurrence of authigenetic minerals such as chlorite, calcite, haematite or glauconite that usually occur in marine sandstones. According to this, outliers observable probably can be explained by data of immature sandstones. The bulk density is characterized by a wide scattering (1.78-2.45 g/ $\mathrm{cm}^{3}$ ) reflecting the highly variable porosity of sandstones (1-33 \%; mean $16.8 \%$; first quartile $12 \%$, third quartile $22 \%$ ), with an average value of $2.14 \mathrm{~g} / \mathrm{cm}^{3}$. Both the matrix and bulk density show a very low variance (Table 2). Porosity data are characterized by a normal distribution with a median and mean of $17.45 \%$. Fifty percent of the data range between 12 and $22 \%$ porosity and outliers do not occur. The water absorption is characterized by a smaller range of quartiles and whiskers, but also shows extreme outliers. The median water absorption under atmospheric conditions $(5.4 \mathrm{wt} \%)$ is markedly lower

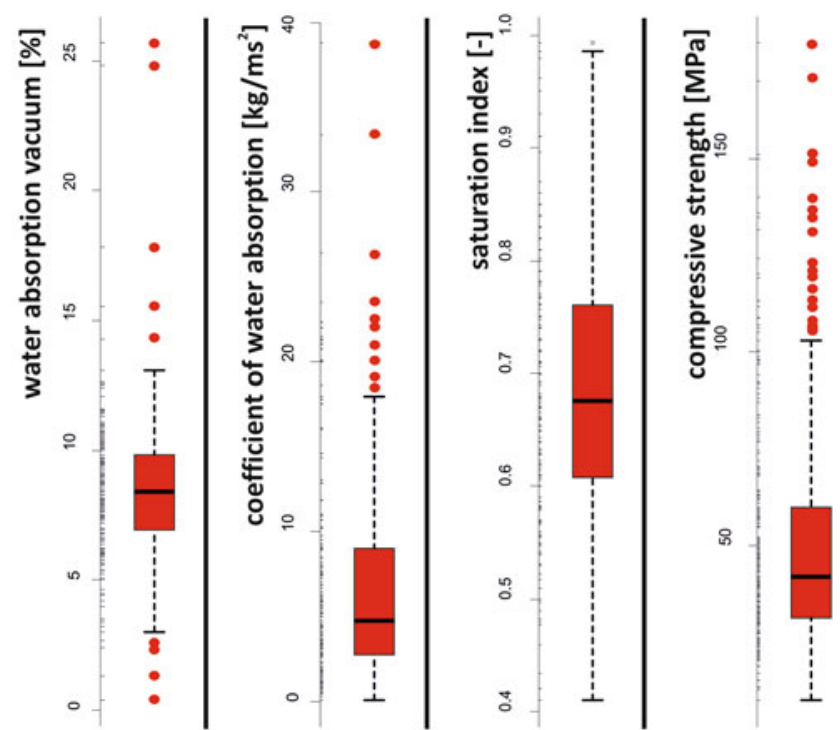

Kirsten (2009) and own samples], $s$ value of 286 as well as compressive strength $[n=246$; David (2006), Kirsten (2009), Mosch and Siegesmund (2007), Holzwarth (1996) and own samples]. The red box indicates the range at which $50 \%$ of the mean data are found and the black bar within the box the median. The red dots represent outliers, which are outside the interquartile ranges

than the water absorption under vacuum (8.5 wt\%). Furthermore, some outliers in both directions are observable. The coefficient of water absorption ( $w$ value) is characterized by a mean of $6.25 \mathrm{~kg} / \mathrm{ms}^{-2}$ and a median of $4.3 \mathrm{~kg}$ / $\mathrm{ms}^{-2}$, by $2.2 \mathrm{~kg} / \mathrm{ms}^{-2}$ for the first quartile and $7.5 \mathrm{~kg} / \mathrm{ms}^{-2}$ for the third quartile. Many outliers are also observable here, but only upwards. The position of the median defines a skewed distribution. The Bad Bentheim sandstone shows the highest coefficient of water absorption with a value of about $40 \mathrm{~kg} / \mathrm{ms}^{-2}$. The saturation index varies from 0.4 to 0.99 (mean 0.67 , median 0.68 ) and only shows one outlier. The compressive strength of all sandstones shows a median of $43 \mathrm{MPa}$ and a mean of $51.68 \mathrm{MPa}$ (first quartile $34 \mathrm{MPa}$, third quartile $63 \mathrm{MPa}$ ). The lowest compressive strength is $12 \mathrm{MPa}$ and the highest one $107 \mathrm{MPa}$. However, some sandstones reach values of up to 160-180 MPa, such as the Permian and Middle Keuper sandstones of Tambach and Barkhausen.

Porosity and compressive strength show marked differences and interrelations between each other, taking into account different lithotypes and their stratigraphic position as documented in Fig. 9 for four selected characteristic sandstones. Poorly altered and strongly compacted sublitharenites such as the Karlshafen and Arholzen Weser sandstones (Fig. 9b; Tables 1, 3) show the lowest porosity. Pure quartz arenites (mean and median porosity: $15 \%$ ) include sandstones with distinct quartz overgrowths and no early infiltration by clay. Sandstones of the Upper Keuper (SE) and of Cretaceous age (OB) commonly fall into this 
Table 2 Mean and variances of data distributions of matrix and bulk density, porosity, water absorption under atmospheric and vacuum conditions, coefficient of water absorption, saturation index and compressive strength

\begin{tabular}{llllllllr}
\hline & $\begin{array}{l}\text { Matrix density } \\
\left(\mathrm{g} / \mathrm{cm}^{3}\right)\end{array}$ & $\begin{array}{l}\text { Bulk density } \\
\left(\mathrm{g} / \mathrm{cm}^{3}\right)\end{array}$ & $\begin{array}{l}\text { Porosity } \\
\text { vol. }(\%)\end{array}$ & $\begin{array}{l}\text { Water abs. } \\
(\mathrm{atm} .) \text { vol. }(\%)\end{array}$ & $\begin{array}{l}\text { Water abs. } \\
(\text { vac. })(\%)\end{array}$ & $\begin{array}{l}\text { Coefficient of } \\
\text { water absorption }\end{array}$ & $\begin{array}{l}\text { Saturation } \\
\text { index }(-)\end{array}$ & $\begin{array}{l}\text { Compressive } \\
\text { strength }(\mathrm{MPa})\end{array}$ \\
\hline Mean & 2.66 & 2.14 & 17.45 & 7.41 & 8.47 & 6.25 & 0.68 & 51.68 \\
Variance & 0.01 & 0.02 & 34.67 & 4.25 & 8.29 & 39.02 & 0.01 & 767.96 \\
\hline
\end{tabular}

Data from David (2006), Fitzner (1990), Grimm (1990), Kirsten (2009), Holzwarth (1996), Mosch and Siegesmund (2007) and own sandstones

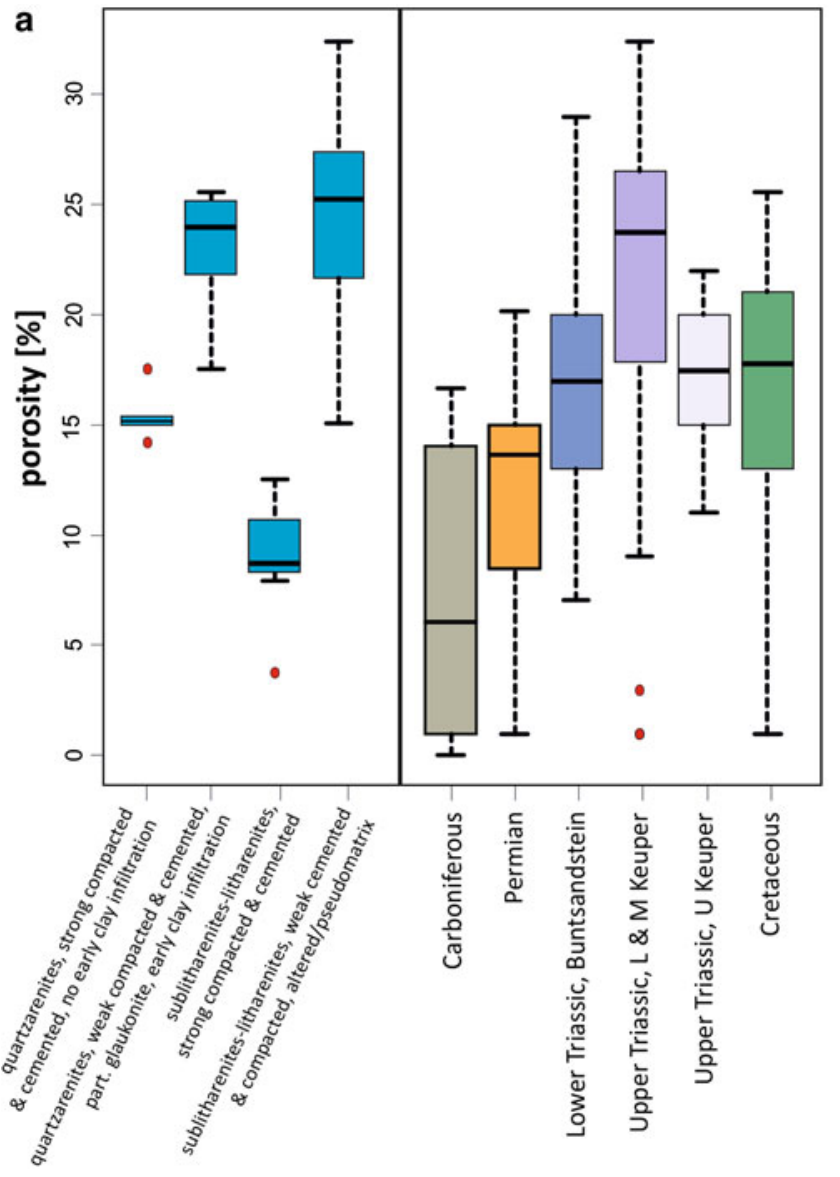

Fig. 9 Whisker plots of a porosity ordered according to lithotype and to stratigraphic age [ $n=258$; David (2006), Fitzner (1970), Kirsten (2009), Holzwarth (1996) and this study] and b compressive strength

group. Weakly compacted and weakly cemented quartz arenites (median $24 \%$ ) and strongly altered sublitharenites-litharenites (median porosity $25 \%$ ) show the highest porosity data. The latter group displays the most distinct scattering and is predominantly represented by sandstones of Lower and Middle Keuper (HS and IS; Tables 1, 3).

Considering the stratigraphic position of the sandstones analysed, the following relationships can be delineated. With increasing stratigraphic age, the porosity generally decreases, indicating that porosity is a function of time and

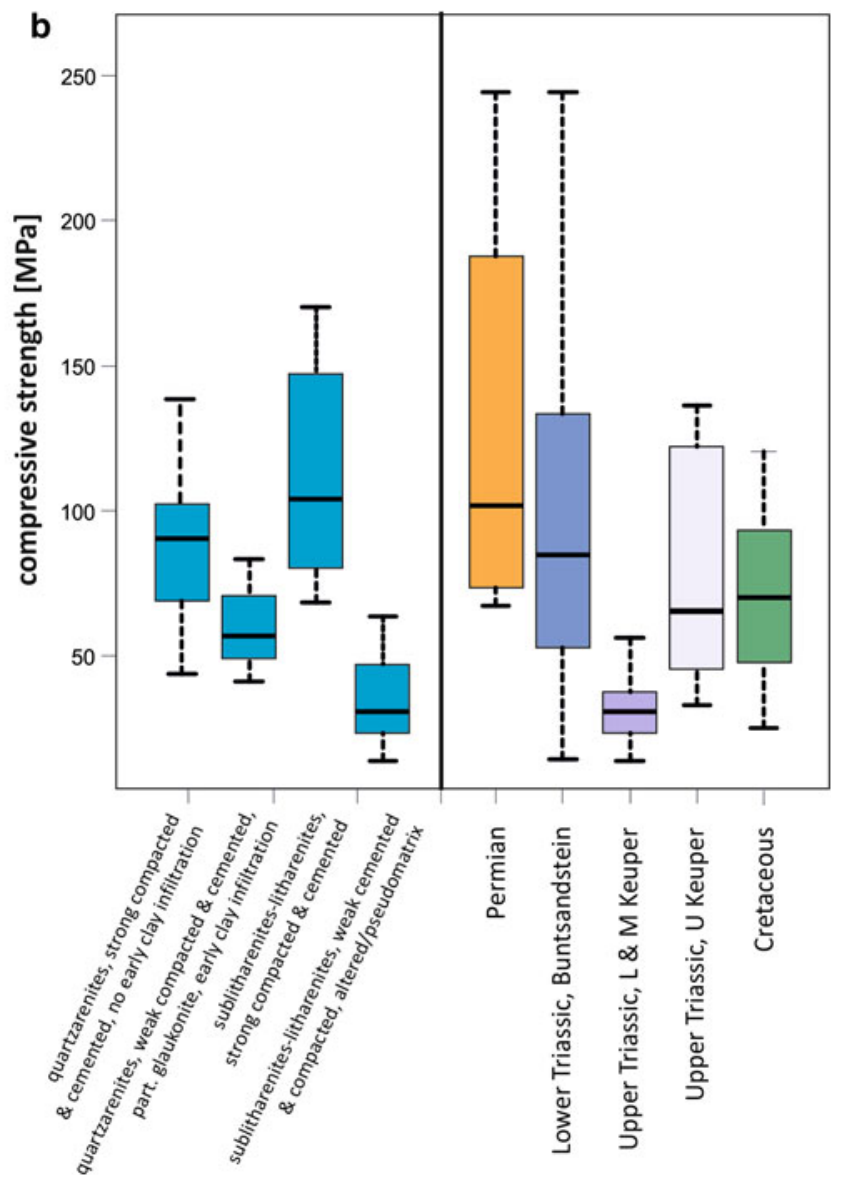

ordered according to lithotype and stratigraphic age. $[n=258$; Chitsazian (1985), David (2006), Fitzner (1970), Kirsten (2009), Holzwarth (1996) and this study]

burial depth (e.g. Wilson 1994, Koch and Sobott 2008). Sandstones of the Buntsandstein show a median porosity of $17 \%$. Those of the Lower and Middle Keuper exhibit the highest porosities (a mean of $24 \%$ ). Similar porosities exist in the sandstones of the Upper Keuper and the Cretaceous, with a mean porosity of $17.5 \%$. Therefore, sandstones of the Upper Keuper and the Cretaceous do not follow the time/burial trend as shown by elder sandstones. This is probably due to the fact that at low burial, the primary parameters of depositional environment and of 
Table 3 Petrophysical characteristics of all 22 sandstones analyzed. These data together with numerous data from the literature is the database for the interrelationships of selected petrophysical parameters and weathering resistance (see Fig. 18/19)

\begin{tabular}{|c|c|c|c|c|c|c|c|c|}
\hline & & Sample & $\begin{array}{l}\text { Porosity } \\
{[\%]}\end{array}$ & $\begin{array}{l}\text { W-value } \\
{[\mathrm{kg} / \mathrm{m} * \mathrm{~s} 2]}\end{array}$ & $\begin{array}{l}\text { Compr. } \\
\text { strength } \\
{[\mathrm{MPa}]}\end{array}$ & $\begin{array}{l}\text { Pore radii } \\
\text { distribution }\end{array}$ & $\begin{array}{l}\text { Hygric } \\
\text { dilatation } \\
{[\mathrm{mm} / \mathrm{m}]}\end{array}$ & $\begin{array}{l}\text { Group of } \\
\text { salt resistance }\end{array}$ \\
\hline \multirow[t]{5}{*}{ Cretaceous } & \multirow[t]{2}{*}{ Upper } & Cotta & 25.20 & 6.10 & $45.00 * *$ & Bimodal & 0.01 & $\mathrm{C}^{* *}$ \\
\hline & & Rüthen & 25.60 & 20.40 & $40.00 * *$ & Bimodal & 0.18 & $\mathrm{C} * *$ \\
\hline & \multirow[t]{3}{*}{ Lower } & Obernkirchen & 17.50 & 2.00 & 100.00 & $\begin{array}{c}\text { Unimodal } \\
\text { equable }\end{array}$ & 0.11 & A \\
\hline & & Hilssandstein & 20.80 & 24.90 & $60.00 * *$ & $\begin{array}{c}\text { Unimodal } \\
\text { equable }\end{array}$ & 0.02 & $\mathrm{C}^{* *}$ \\
\hline & & Bentheim & 25.60 & 40.70 & 95.00 & $\begin{array}{c}\text { Unimodal } \\
\text { equable }\end{array}$ & 0.02 & A \\
\hline \multirow[t]{10}{*}{ Upper Triassic } & \multirow[t]{4}{*}{ Rhät } & Velpke & 24.70 & 33.40 & $50.00 * *$ & $\begin{array}{c}\text { Unimodal } \\
\text { equable }\end{array}$ & 0.03 & $\mathrm{~B}^{* *}$ \\
\hline & & Seebergen & 15.80 & 1.80 & 108.91 & $\begin{array}{r}\text { Unimodal } \\
\text { unequal }\end{array}$ & 0.01 & A \\
\hline & & Röhnberg & 21.87 & 11.85 & 32.83 & $\begin{array}{l}\text { Unimodal } \\
\text { equal }\end{array}$ & 0.15 & $\mathrm{C}$ \\
\hline & & Hockeln & 15.40 & 3.40 & $65.00 * *$ & Bimodal & 0.19 & $\mathrm{C}^{* *}$ \\
\hline & \multirow[t]{4}{*}{ Schilfsandstein } & Barkhausen & 3.80 & 0.40 & $170.00 *$ & Bimodal & 0.93 & A \\
\hline & & Schötmar & 10.30 & 0.90 & $80.00^{*}$ & Bimodal & 1.11 & $\mathrm{~B} * *$ \\
\hline & & Hindleben & 22.07 & 18.05 & 16.10 & Bimodal & 5.21 & $\mathrm{C}$ \\
\hline & & Sander & 17.00 & 20.05 & 54.71 & Bimodal & 1.25 & $\mathrm{C}$ \\
\hline & \multirow[t]{2}{*}{ Letten-kohlenkeuper } & Ingersleben & 27.71 & 31.03 & 23.10 & $\begin{array}{c}\text { Unimodal } \\
\text { equable }\end{array}$ & 2.80 & $\mathrm{C}$ \\
\hline & & Schleerith & 15.26 & 2.01 & 55.00 & Bimodal & 0.98 & $\mathrm{C}$ \\
\hline \multirow[t]{4}{*}{ Lower Triassic } & \multirow[t]{4}{*}{ Middle Buntsandstein } & Karlshafen & 7.90 & 0.50 & 119.14 & $\begin{array}{r}\text { Unimodal } \\
\text { unequal }\end{array}$ & 1.35 & A \\
\hline & & Arholzen & 10.68 & 1.20 & 79.43 & $\begin{array}{r}\text { Unimodal } \\
\text { unequal }\end{array}$ & 1.39 & A \\
\hline & & Lobach & 11.94 & 1.35 & $94.00 *$ & $\begin{array}{r}\text { Unimodal } \\
\text { unequal }\end{array}$ & 0.60 & B \\
\hline & & Uder & 23.26 & 19.59 & $48.00 *$ & $\begin{array}{c}\text { Unimodal } \\
\text { equable }\end{array}$ & 0.58 & B \\
\hline \multirow[t]{2}{*}{ Permian Lower } & \multirow[t]{2}{*}{ Rotliegend } & Bebertal & 9.68 & 0.93 & 68.00 & $\begin{array}{l}\text { Unimodal } \\
\text { unequal }\end{array}$ & 0.54 & B \\
\hline & & Tambach & 8.28 & 0.58 & $160.00 *$ & Bimodal & 0.57 & A \\
\hline Carboniferous & & Ibbenbüren & 12.50 & 1.00 & $120.00 * *$ & $\begin{array}{l}\text { unimodal } \\
\text { Unimodal } \\
\text { unequal }\end{array}$ & 0.53 & $\mathrm{~A}^{* *}$ \\
\hline
\end{tabular}

* Bartelsen (2008)/Ruedrich et al. (2011)

** Seidel (2004)/Ruedrich et al. (2005)

eogenetic cementation as well as early formed secondary porosity always have a major effect. Moreover, they are not completely overprinted and hidden by deeper burial alteration and homogenization.

Also, the distribution of compressive strength was grouped according to the lithotypes and stratigraphic position (Fig. 9b). The median for strong compacted and/or cemented quartz arenites amounts to $87 \mathrm{MPa}$, whereas weak compacted quartz arenites exhibit with $56 \mathrm{MPa}$ a distinct lower compressive strength. Sublitharenites, which contain 5-25\% unstable lithic rock fragments, are strongly compacted and cemented and have a median compressive strength of $103 \mathrm{MPa}$. Weakly compacted and cemented, altered sublitharenites-litharenites exhibit the lowest compressive strength with $37 \mathrm{MPa}$ as median. The compressive strength dependent on stratigraphy shows for Permian and Lower Triassic (Buntsandstein) sandstones the highest values, whereas in sandstones belonging to Middle and Lower Keuper (Upper Triassic) the lowest compressive strength is observable (median: $37 \mathrm{MPa}$ ). 
Three different types of sandstones can be recognized based on the pore radii distribution (I-bimodal, II- unimodal unequal and III-unimodal equal). Predominantly, litharenites of Upper Triassic age (Lower and Middle Keuper, HS, SA, SL; Tables 1, 3) with very low maturity show a bimodal pore radii distribution (Fig. 10I). Microsized pores are caused by the alteration of less stable components and/or the presence of a pseudomatrix. The second maximum of capillary pores reflects relics of primary intergranular porosity, which was closed by different degrees due to cementation and compaction. Unimodal unequal (Fig. 10II) distributions of pore radii can be predominantly observed in sublitharenites, but they can also occur in quartz arenites. In sublitharenites, this pore radii distribution can be attributed to moderate to well sorting, weak alteration of unstable grains and a moderate degree of cementation and compaction as documented by the Weser sandstones of Lower Triassic age (Buntsandstein, KA, AH, UD). Quartz arenites, which show such a distribution of pore radii, are generally well sorted and exhibit a more immature character due to the infiltration of clay minerals (Cretaceous and Upper Triassic sandstones; Upper Keuper, SE). Unimodal equal distributions of pore radii (Fig. 10III) are mainly found in well-sorted highly mature quartz arenites, in which no infiltration of clay minerals occurred as documented by the Cretaceous sandstones (VE, RÜ, HI, OBI). In general, an increase of maturity is correlated with the pore radii distribution from bimodal to unimodal unequal to unimodal equal.

No correlation seems to exist between grain size and compressive strength or between grain size and porosity (Fig. 11). According to Schießl and Alfes (1990), sandstones with smaller grain size should exhibit higher strength, since the amount of grain contacts per volume should be higher in finer grained sandstones. Indeed, Schieß1 and Alfes (1990) take into account the number of grain contacts. However, the kind of grain contact stays unconsidered. Thereby, a quartzquartz grain contact should behave different from a quartzlithoclast, or quartz-feldspar grain contact. In consequence, independent of grain size, the lithology (content of mechanical stable/unstable grains) should have higher impact on strength than grain size. Müller et al. (2002) observed a linear relationship between porosity and grain size, whereby with increasing grain size a decrease of porosity should be observable. Based on the large data set in this study, this cannot be confirmed. This investigation assumes that modification of pore space during diagenesis and initial sorting mainly rules the final porosity, whereby the grain size has little effect.

The bivariate analysis of correlations between petrophysical properties commonly reflects a linear or exponential relationship (Fig. 12). In sandstones with similar matrix density as the siliciclastic detrital grains, porosity correlates to bulk density (correlation coefficient $=$ 0.4114 ). High porosity is related to low bulk density and vice versa (Fig. 12a). Newly formed mineral phases and/or detrital minerals with different density (e.g. glauconite, calcite, dolomite etc.) will result in a negative correlation. The average value for all sandstones amounts to $15 \%$ porosity at a bulk density of $2.25 \mathrm{~g} / \mathrm{cm} 3$. Compressive strength decreases exponentially with an increasing coefficient of water absorption (Fig. 12b; correlation coefficient $=0.3497$ ). Here, the average value of the probability ellipsoid for all the sandstones investigated amounts to $70 \mathrm{MPa}$ at $5 \mathrm{~kg} / \mathrm{ms}^{-2}$. The water absorption, dependent on porosity, increases linearly with a correlation coefficient of $R=0.46$ under vacuum and $R=0.37$ under atmospheric pressure (Fig. 12c). The ultrasonic velocity shows a linear correlation $(R=0.4712)$ to porosity (Fig. 12d). High velocity correlates with low porosity. The average value of $80 \%$ probability ellipsoid amounts to $2,700 \mathrm{~m} / \mathrm{s}$ and a porosity of $13.5 \%$. Also, a linear relationship between ultrasonic velocity and compressive strength is observable. Here, the velocity increases with increasing compressive strength (Fig. 10e; $R=0.6581$ ). The average value of the ellipsoid equals $2,700 \mathrm{~m} / \mathrm{s}$ and $50 \mathrm{MPa}$. The relationship between compressive strength, flexural strength $(R=0.6074)$ and porosity is illustrated in Fig. 12f: in general, both strengths decrease with increasing porosity. Therefore, the gradient between porosity and compressive strength is higher than the flexural strength. Furthermore, a positive linear relationship between compressive strength and flexural strength (Fig. 12g; $R=0.6074$ ) and between compressive strength and bulk density ( $R=0.3993$ ) is obvious (Fig. 12h).

The regression analysis of basic parameters shows besides the approximate linear relationships, a partially distinct scattering. This distribution and interrelationship of parameters can be explained in greater detail, when also considering characteristics of petrographic composition and fabric. These interrelationships between strength and porosity to parameters such as pore radii distribution, grain contact, degree of alteration (i.e. maturity) and content of unstable lithic fragments is determined with confidence regions of $80 \%$ probability (Fig. 13). Sandstones with a unimodal equal pore radii distribution in direction show a higher compressive strength than sandstones with unimodal unequal pore radii distributions (Fig. 13a). In contrast, sandstones with a bimodal pore radii distribution show a larger scattering of data as indicated by the ellipsoid with $80 \%$ probability covering a wider range.

The interrelationships between compressive strength, porosity and type of grain contacts are well documented (Fig. 13b). Sandstones with low compressive strength and high porosity mainly exhibit pointed and elongated grain contacts. In contrast, sandstones with sutured and concaveconvex contacts exhibit higher compressive strengths. 


\section{increase of maturity}

\section{(I) bimodal}

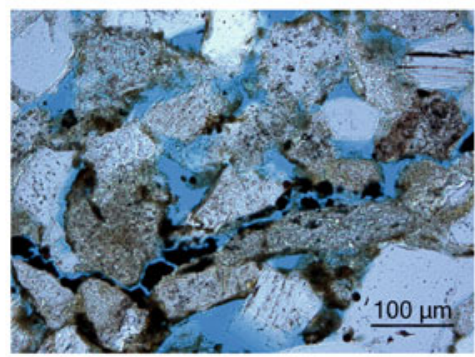

II unimodal unequal

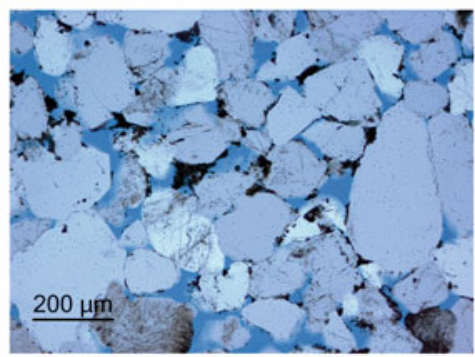

III) unimodal equable

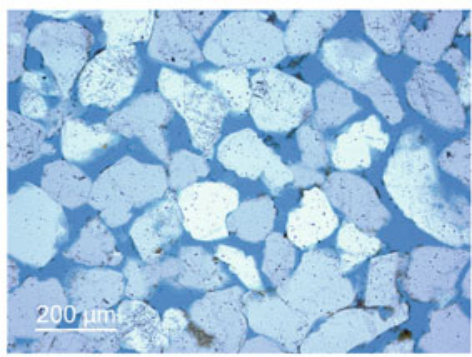

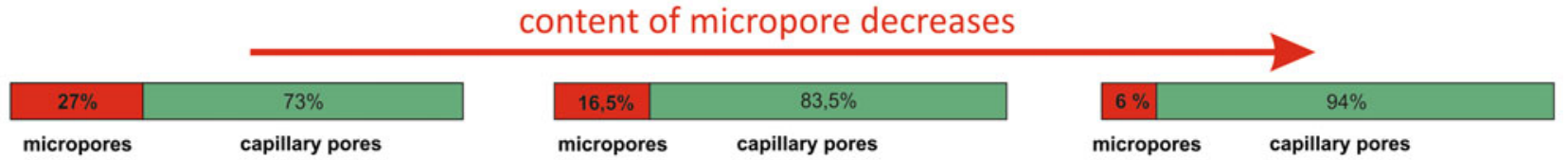
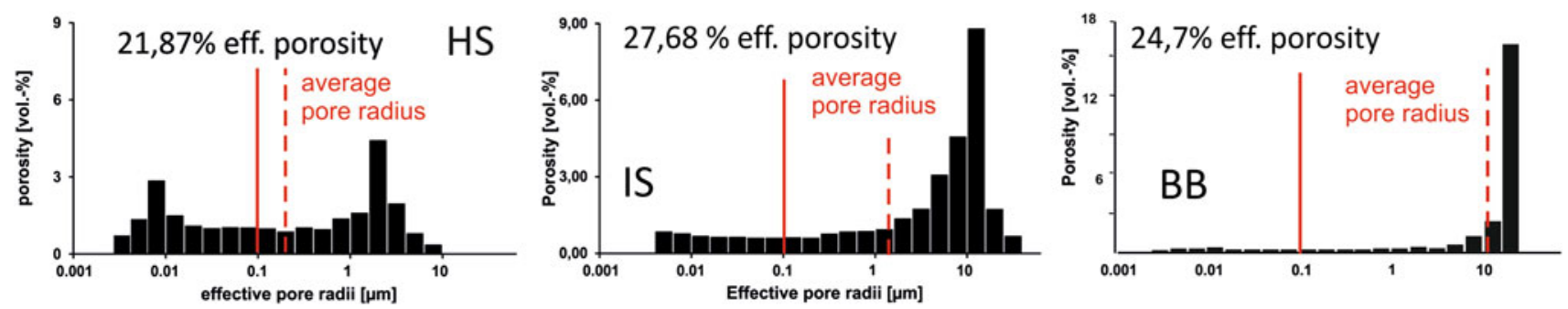

Fig. 10 Schematic documentation of pore radii distribution, development of maturity and amount of micropores: $(I)$ bimodal with two maxima, (II) unimodal unequal and (III) unimodal equable. The bars indicate the ratio of micropores to capillary pores. The vertical red lines in the diagrams indicate the boundary between micro- and capillary pores and the dashed line the average pore radius
Fig. 11 Diagrams showing the relationship between porosity and grain size, and between compressive strength and grain size dependent on sandstone type. (Fitzner 1970, $n=22$; David 2006, $n=56$; Kirsten 2009, $n=45$; Grimm 1990, $n=72$, this study $=22$ )

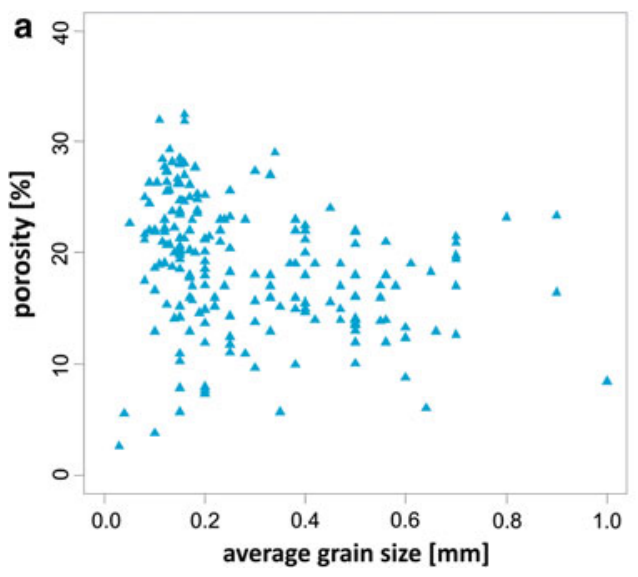

Although the average data of the compressive strength for concave-convex grain contacts in the sandstones is lower than the data for sutured grain contacts, outliers of sandstones with concave-convex grain contacts show strengths with up to $170 \mathrm{MPa}$. Therefore, these two types of grain contacts (concave-convex and sutured) can probably be both considered equivalent and stabilizing. The interrelationship between compressive strength and degree of

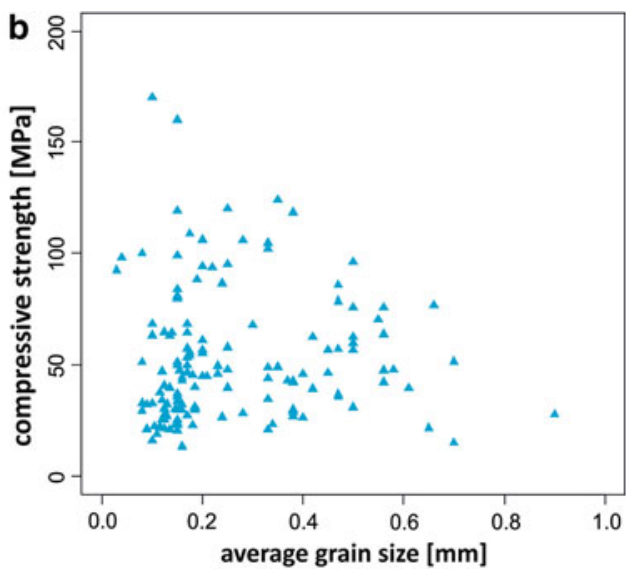

alteration to maturity is documented in Fig. 13c. Sublitharenites and litharenites with highly altered feldspars and unstable lithic fragments and high amounts of chlorite in pseudomatrix exhibit a very low compressive strength and a high porosity. Quartz arenites, which show a low degree of compaction and cementation, also display low compressive strengths and high porosities. Besides the pore radii distribution, type of grain contacts and the degree of 
alteration, the compressive strength is also related to the content of unstable lithic fragments. Generally, a decrease of the compressive strength with increasing amounts of unstable lithic fragments is observable as shown by sandstones with up to 5, 15 and $30 \%$ unstable lithic fragments. Furthermore, the interrelationship of these three groups to porosity is indicated by the inclination of the three correlation lines (Fig. 13d). The main reason for this interrelationship is the content of unstable lithic fragments such as volcanic and clayey clasts, which commonly occur in sandstones of Upper Triassic (Lower- and Middle-Keuper) age.

Also within the water absorption, further details are recognizable: The coefficient of water absorption and the porosity also show interrelationships to the pore radii distribution (Fig. 14a) and the different rock types with varying degrees of alteration (Fig. 14b). Ellipsoids confirm that sandstones with unimodal equal pore radii distribution exhibit higher $w$ values in dependence to porosity, whereas sandstones with unimodal unequal pore radii distribution show much lower $w$ values. Medium ranges show sandstones with bimodal pore radii distribution. This probably can be attributed to the high content of capillary pores, which promote the absorption of water in the pore space. Furthermore, the coefficient of water absorption is highest for weakly cemented and less compacted quartz arenites. In contrast, quartz arenites that are more compacted and cemented show less absorption of capillary water. Sublitharenites, which are strongly compacted and cemented, show low to medium water absorption and low porosity. The $80 \%$ confidence region of strongly altered sublitharenites covers a wide range and overlap with the confidence region of strongly compacted quartz arenites and sublitharenites. Well-sorted sublitharenites show the highest porosity and also a high degree of water absorption.

The "Houseknecht diagram" is used to evaluate which diagenetic processes reduced the intergranular volume in order to determine the reservoir quality of a sandstone (Fig. 15; Houseknecht 1987). In the present paper, the Houseknecht diagram is used to illustrate the interrelationship between amount and type of cement as well as intergranular pore volume (minus cement porosity) and compressive strength. Generally, the compressive strength increases with decreasing amount of inter granular volume in dependence on the type of mineral cement (Fig. 15). Sublitharenites containing a clay cement or pseudomatrix show a decrease of compressive strength with increasing intergranular pore volume and a decreasing amount of cement. Sublitharenites, which are cemented by silica, carbonate and $\mathrm{Fe}$ phases, exhibit the highest strength (105-150 MPa), an intergranular volume between 20 and $28 \%$ and content of 10-20\% cement. These sandstones are Carboniferous, Permian and Lower Triassic in age.
Quartz arenites with an intergranular volume of about $20-25 \%$ and a low amount of cement $(\sim 5-8 \%)$ show a compressive strength ranging between 70 and $100 \mathrm{MPa}$.

\section{Weathering properties}

Two of the most important weathering mechanisms in sandstones are hygric dilatation and salt splitting. In the literature, the data regarding the weathering properties of sandstones are commonly based on hygric dilatation under water saturation and on salt splitting tests with different types of salt (e.g. sodium chloride, sodium sulphate, magnesium sulphate). The data used for the diagram in Fig. 17 are predominantly based on salt splitting tests using $\mathrm{Na}_{2}\left(\mathrm{SO}_{4}\right)$.

The mean hygric dilatation of all sandstones analysed is $0.49 \mathrm{~mm} / \mathrm{m}$ (highest values range from 1.2 to $5.21 \mathrm{~mm} / \mathrm{m}$; Fig. 16). Quartz arenites show a very low hygric dilatation $($ mean $=0.05 \mathrm{~mm} / \mathrm{m})$. Sublitharenites and litharenites show a dilatation with a mean of $0.59 \mathrm{~mm} / \mathrm{m}$. Sorting the hygric dilatation according to stratigraphic age, sandstones of the Upper Keuper (Rät) and Cretaceous (Wealden) show very low dilatation, although these quartz arenites can contain low amounts of swelling clay minerals (e.g. the Bad Bentheim and Röhnberg sandstones, Tables 1, 3). This may be due to the position of clay minerals within the pore space and also the type of pore radii distribution, which is almost unimodal equal and does not promote hygric dilatation. Distinctly higher values belong to the sandstones of the Lower Triassic Buntsandstein, which exhibit a mean hygric dilatation of $0.56 \mathrm{~mm} / \mathrm{m}$ and a wider scattering of the first and third quartile. Lower and Middle Keuper sandstones show a narrow range of hygric dilatation, but also some very high values of up to $5.21 \mathrm{~mm} / \mathrm{m}$, which reflect litharenites of the Upper Triassic (Lettenkohlenkeuper and Schilfsandstein). This extraordinary high value belongs to the Middle Keuper Hindfelden sandstone (Table 3), which occurs in the Thuringia Basin. Sandstones of Cretaceous show with $0.12 \mathrm{~mm} / \mathrm{m}$ the lowest hygric dilatation in average.

In salt splitting tests (Fig. 17), $28.3 \%$ of all sandstones (Group A) analysed show no loss of material up to 100 cycles. $32.6 \%$ of the sandstones (Group B) lose $50 \%$ of their material in the range of $30-40$ cycles. $39.1 \%$ of the sandstones (Group C) show $50 \%$ material loss already during the first 15 cycles. Sandstones with the best salt resistance (Group A; Upper Keuper and Cretaceous, Table 3) are predominantly composed of quartz arenites. They seldom fall into Group B or C, such as the Röhnberg or Cotta sandstone, which is very weakly compacted and cemented and exhibits high amount of clay cutanes on detrital quartz grains, respectively, a clayey matrix like sandtone Cotta. Litharenites are primarily positioned in 

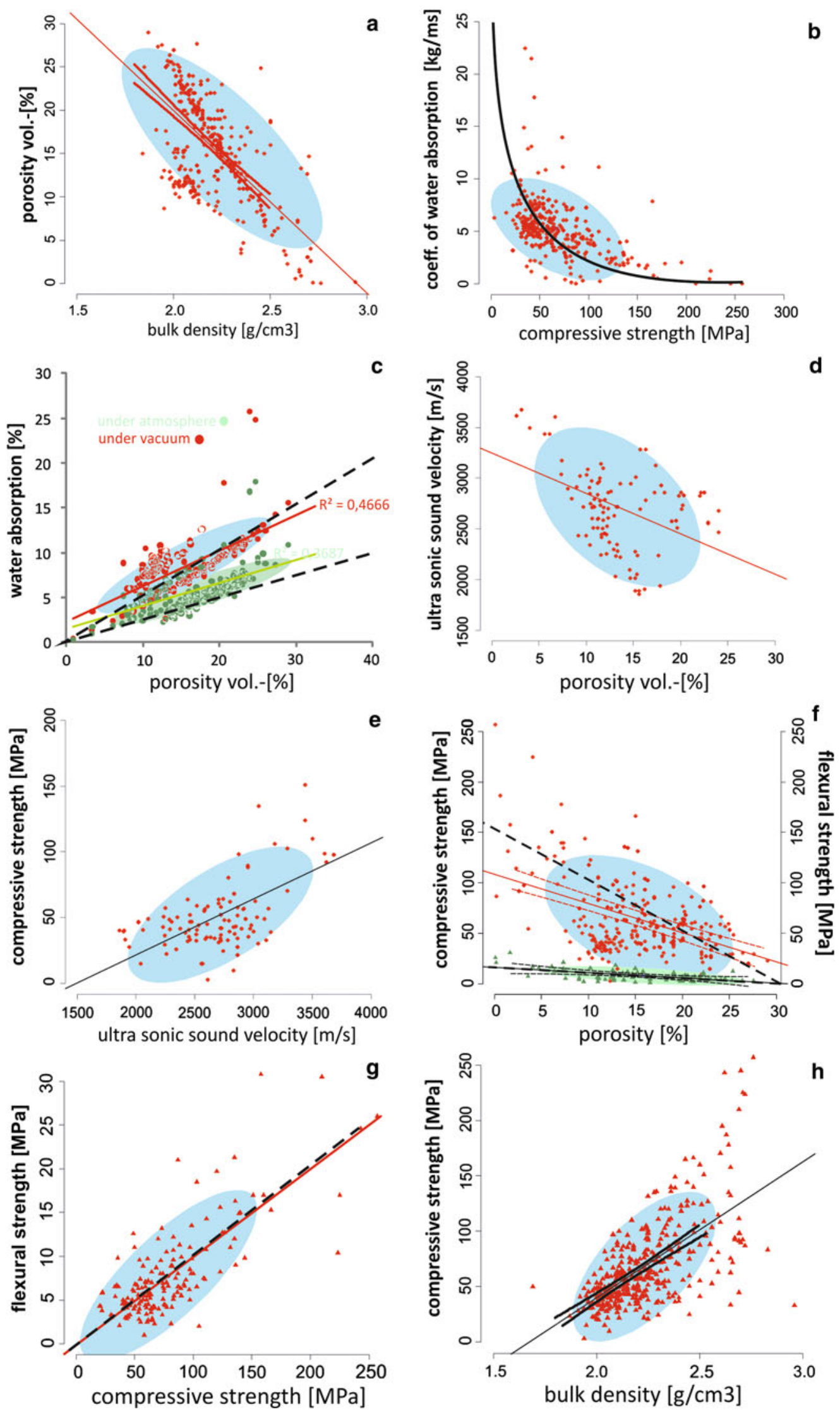
4Fig. 12 Regression diagrams between different petrophysical properties. The blue ellipsoid predicts an $80 \%$ probability of the data. The black dashed line next to the regression line represents the ratio between two properties in some cases. a Porosity versus bulk density [ $n=305$; Grimm (1990), Kirsten (2009), David (2006), Holzwarth (1996), Mosch and Siegesmund (2007), Wenzel and Häfner (2003), and this study], b capillary water uptake versus compressive strength $[n=305$; David (2006), Holzwarth (1996), Kirsten (2009), Mosch and Siegesmund (2007), and this study], c water uptake under atmospheric pressure and under vacuum versus porosity $[n=214$; Kirsten (2009), David (2006), Grimm (1990), and this study], d ultrasonic velocity versus porosity $[n=89$; Fitzner (1970), Kirsten (2009), and this study], e compressive strength versus ultrasonic velocity [ $n=89$; Fitzner (1970), Kirsten (2009), and this study], f compressive and flexural strength versus porosity, $\mathbf{g}$ flexural strength versus compressive strength and $\mathbf{h}$ compressive strength versus bulk density

Group C, and subordinate in Group B. In contrast, sublitharenites show no clear preference to group since every group is represented. The strongly compacted Weser sandstones mostly belong to Group A or B. In contrast, the sandstones of the Lower and Middle Keuper (Schilfsandstein, Lettenkohlenkeuper, e.g. SA, SL, HS, IS; Table 3) mainly fall into Group C and subordinate in Group B.

The interrelationship between the coefficient of water absorption and porosity in the three groups of salt resistance is documented in Fig. 18a. Sandstones with a high porosity and a high coefficient of capillary water absorption show the lowest resistance against salt splitting. In contrast, sandstones with low porosity and low capillary water uptake show a very high resistance against salt splitting. Similar interrelationships are obvious when considering the compressive strength versus porosity (Fig. 18b). Sandstones with high compressive strength and low porosity are most stable against salt splitting, in contrast to sandstones with low compressive strength and high porosity, which show the lowest salt resistance. In Fig. 18c, four classes of hygric dilatation are defined that show a distinct overlapping of the confidence ellipsoids. Sandstones with low compressive strength and high porosity primarily belong to the classes of higher hygric dilatation.

Four groups of hygric dilatation can be identified when the sorption and the amount of micropores are regarded (Fig. 18d). Samples with different amounts of micropores and sorption plot in markedly different ellipsoids of $80 \%$ confidence. Sandstones which show a hygric dilatation of less than $0.1 \mathrm{~mm} / \mathrm{m}$ have the lowest amount of micropores. Nevertheless, they can show a sorption ranging between 0.2 and $1.5 \mathrm{wt} \%$. Sandstones with a hygric dilatation of $0.1-0.5 \mathrm{~mm} / \mathrm{m}$ have a higher amount of micropores and water absorption up to $4.5 \mathrm{wt} \%$. Sandstones with a hygric dilatation of $0.4-5.0 \mathrm{~mm} / \mathrm{m}$ show the best normal linear correlation between sorption and the amount of micropores.
Multicorrelation of sandstone properties using principal component and cluster analysis

The principal component analyses consider the porosity, capillary water absorption, compressive strength, salt resistance as well as hygric dilatation data (data from present study, Bartelsen 2008; David 2006; Seidel 2004, Fig. 19). An orientation of variables within the diagram confirms a positive linear correlation between compressive strength and the number of cycles in salt splitting tests as well as between capillary water uptake and porosity. Between compressive strength, salt resistance and capillary water uptake as well as porosity, a negative correlation is well expressed. Hygric dilatation and porosity show no correlation to each other, whereas a positive correlation of compressive strength to salt resistance is obvious (Table 4).

The three groups of different pore radii distribution (Fig. 19a) form clear clusters in the principal component analysis. The variance of sandstones with unimodal equal pore radii distribution is characterized by a high capillary water uptake and porosity. In contrast, the variance of samples with unimodal unequal pore radii distribution is concentrated in the field of salt resistance and compressive strength. The sandstone data exhibiting a bimodal pore radii distribution show more scattering and are characterized by a high hygric dilatation and lower compressive strength.

Adding lithotypes to the principal component analysis (Fig. 19b), it is obvious that quartz arenites show a unimodal equal pore radii distribution. Strongly compacted and cemented sublitharenites-litharenites are characterized by variable data with regard to salt weathering, compressive strength and hygric dilatation. Most of these sandstones show high compressive strength and are resistant against salt splitting, but the hygric dilatation can vary significantly. These sandstones predominantly show a unimodal unequal pore radii distribution. In contrast, sublitharenites-litharenites with a high content of unstable lithic fragments and/or pseudomatrix show a higher hygric dilatation and high porosity with a well-developed tendency for capillary water absorption. These sandstones primarily show a bimodal pore radii distribution.

By including micropores, the primary intergranular pore volume (minus cement porosity), unstable lithic fragments and the sorption into the principal component analysis (Fig. 19c) further interrelationships can be recognized. The hygric dilatation shows a positive correlation to the amount of unstable lithic fragments and sorption. Subordinately, an interrelationship between the amount of micropores and degree hygric dilatation can also be observed. The present porosity always shows a positive linear correlation to the primary intergranular pore volume (minus cement porosity) in the sandstones analysed. 

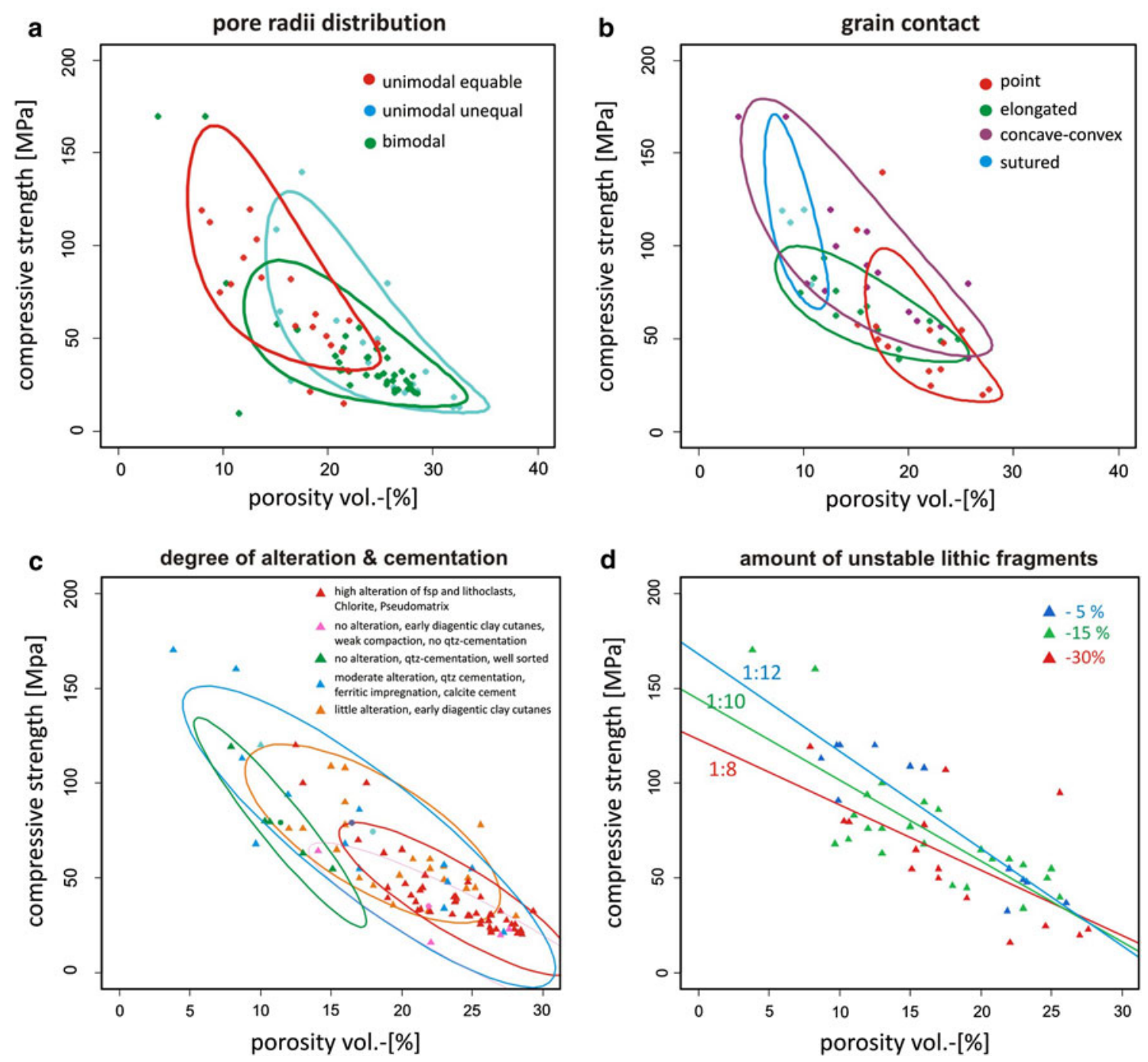

Fig. 13 Diagrams showing the interrelationship between strength and porosity to a pore radii distribution $(n=76)$, $\mathbf{b}$ type of grain contacts $(n=120)$, c degree of alteration and cementation $(n=120)$ and

d amount of unstable lithic fragments $(n=120)$. Data origin from this study, Bartelsen (2008), David (2006), Fitzner (1970), Kirsten (2009) and Seidel (2004)

Weakly compacted quartz arenites with minor amounts of cement are characterized by high coefficients of water absorption, a high amount of primary intergranular pores and high porosity as well as a small hygric dilatation, low sorption and minor amounts of micropores. These sandstones commonly show moderate to low salt resistance and compressive strength. The extraordinary Bad Bentheim sandstone exhibits a high capillary water absorption and high porosity and is characterized by medium compressive strength and high salt resistance.

Strongly compacted and cemented quartz arenites are characterized by high compressive strength and salt resistance and low amounts of intergranular pore volume as well as a low coefficient of water absorption, small amounts of micropores and a very low sorption. Strongly compacted and cemented sublitharenites-litharenites are

characterized by small amounts of intergranular pores, minor water absorption and a low degree of hygric dilatation combined with a low amount of micropores. Strongly altered sublitharenites-litharenites show a high degree of water absorption and many micropores as well as a low amount of intergranular pores. The Hindfelden sandstone exhibits an extraordinarily high degree of hygric dilatation, many micropores and unstable lithic fragments, and low salt resistance and compressive strength.

In the cluster analysis shown in Fig. 19d, the different lithotypes based on similar material and weathering properties show a very good grouping (I, II, III, IV, and V) and indicate a well-expressed weathering resistance. Sandstones showing low salt resistance and/or distinct hygric swelling are found in the pink ellipsoid (I). They consist of strongly altered sublitharenites-litharenites (e.g. the 


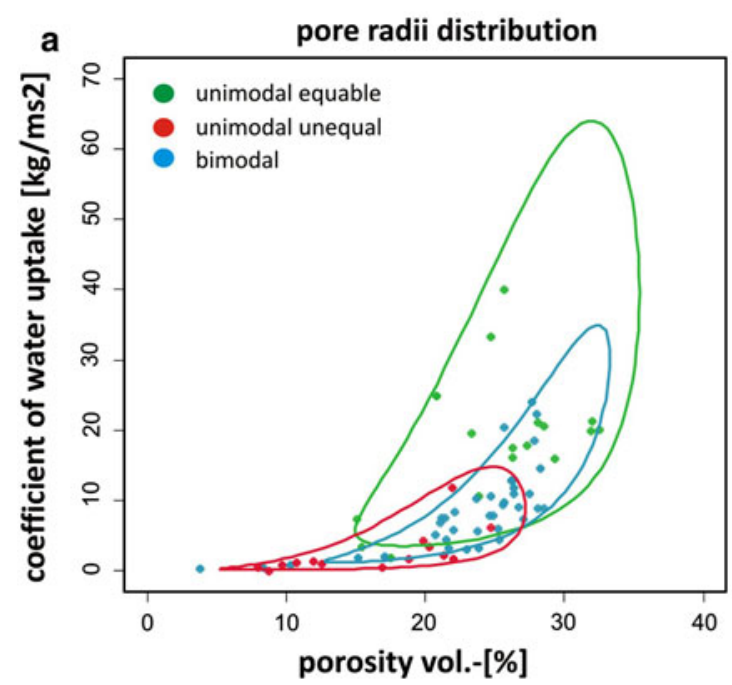

Fig. 14 Coefficient of water absorption dependent on porosity. Ellipsoids mark confidence regions of $80 \%$ probability of a pore radii distribution ( $n=92$, Kirsten 2009; David 2006 and data of this

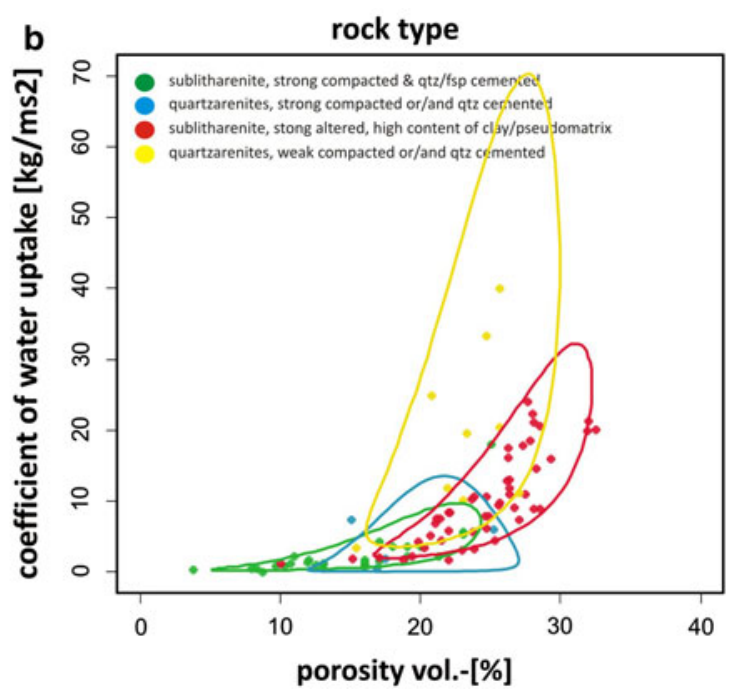

study) and b rock types and degree of alteration, sorting and compaction $[n=87$, Fitzner 1970; Kirsten 2009 and data of this study]
Fig. 15 Houseknecht diagram with selected sandstones and data of compressive strength

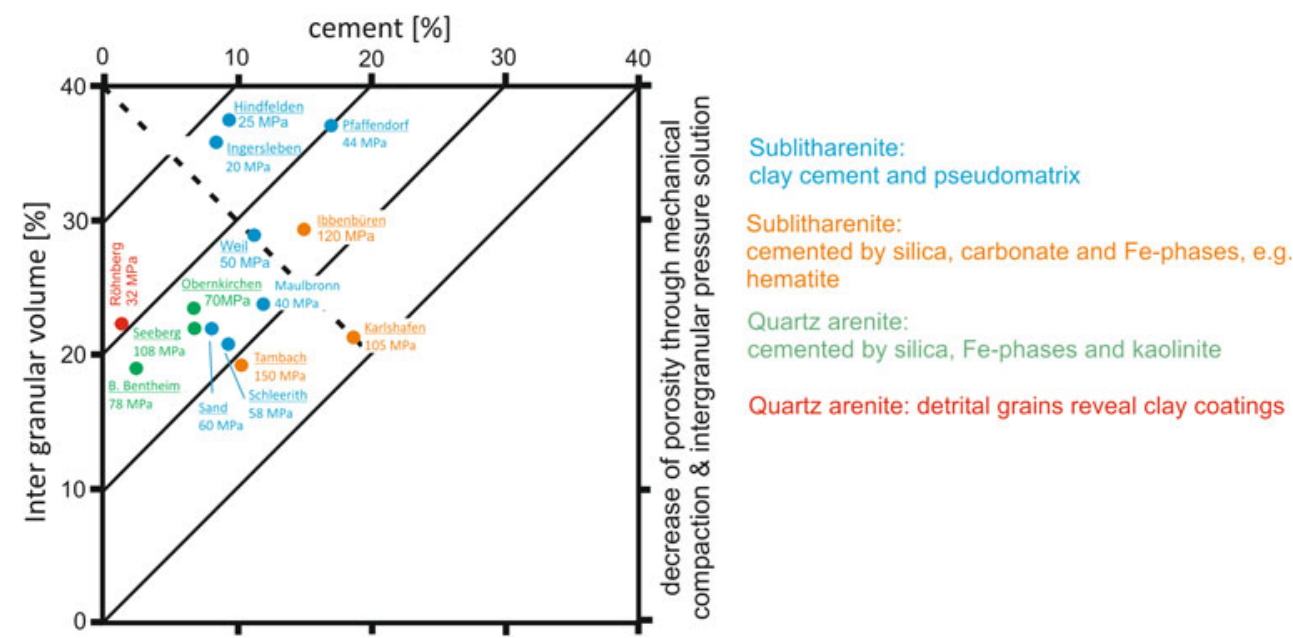

Ingersleben and Hindfelden/Middle and Lower Keuper sandstones), but also weakly compacted quartz arenites (of Cretaceous and Lower and Triassic/Buntsandstein, e.g. sandstone Rüthen, Hilssandstein, Uder and Velpke). Sandstones that are found in the orange ellipsoid are mostly quartz arenites and sublitharenites-litharenites, which are weakly compacted and cemented, medium to low strength, show a porosity $>20 \%$ and a high coefficient of water absorption. Furthermore, they are characterized by a medium to low weathering resistance, since they only show weak salt resistance. Sandstones belonging to this group are e.g. Röhnberg and Cotta. In Group III, altered sublitharenites-litharenites and weakly compacted quartz arenites can be found. They are characterized by porosity between 10 and $20 \%$, medium strength as well as medium weathering resistance, which is confirmed by their affiliation in salt Group B and low hygric dilatation. Sandstones belonging to this group are Schleerieth, Sander (Upper Triassic/Lower and Middle Keuper) and Hockeln (Upper Triassic, Rhät). Sandstones of Group IV include the sublitharenites-litharenites, which are strongly compacted and cemented such as the Weser sandstones and also the Permian Tambach and Bebertal sandstones. They are characterized by a well-pronounced salt resistance and also a distinct hygric swelling. Within Group V, strongly compacted quartz arenites and sublitharenites are found, which are characterized by low porosity, high strength, low water absorption and, therefore, a very well-developed weathering resistance, since they only show little hygric dilatation and high salt resistance. Sandstones belonging to 


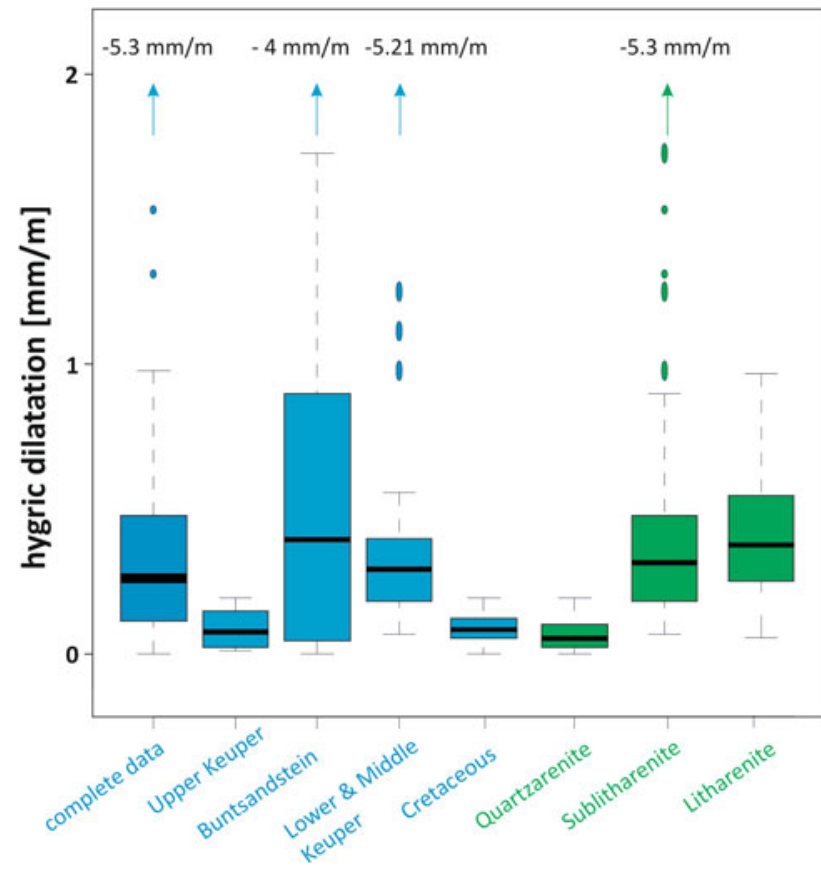

Fig. 16 Hygric dilatation of all sandstones analysed and from literature of Kirsten (2009), David (2006), Holzwarth (1996) (Upper Keuper, Lower and Middle Buntsandstein, Lower and Middle Keuper; quartz arenites, lithic arenites and sublitharenites)

this group are, e.g. Seebergen, Arholzen, Obernkirchen and Ibbenbüren. Only sample Bad Bentheim does not fit in any group and is separated from the remaining sandstones.

To summarize, the sandstones which belong to Group IV and $\mathrm{V}$ can be defined as weathering resistant, whereas sandstones of Group I and II only show weak weathering resistance. Group III includes samples that can be defined as medium resistant.

\section{Discussion and conclusions}

The statistical analyses from the combined petrographical, petrophysical and fabric data of the sandstones with differing geological age and composition show that multiple interlocking parameters control their material properties. In the sandstones analysed, the univariate data distribution highlights the interrelationships between compressive strength and amount of porosity with lithology and stratigraphic position. Furthermore, a general decrease of porosity in dependency to burial time and depth can be observed, which confirms the study of Koch and Sobott (2008) and the modelling of Scherer (1987) and Waples (2002). The sorting as textural parameter of the sandstones simultaneously affects the porosity. In contrast, no linear correlation is reflected by the average grain size to porosity, which was also found out by studies of unconsolidated sands (Beard and Weyl 1973).

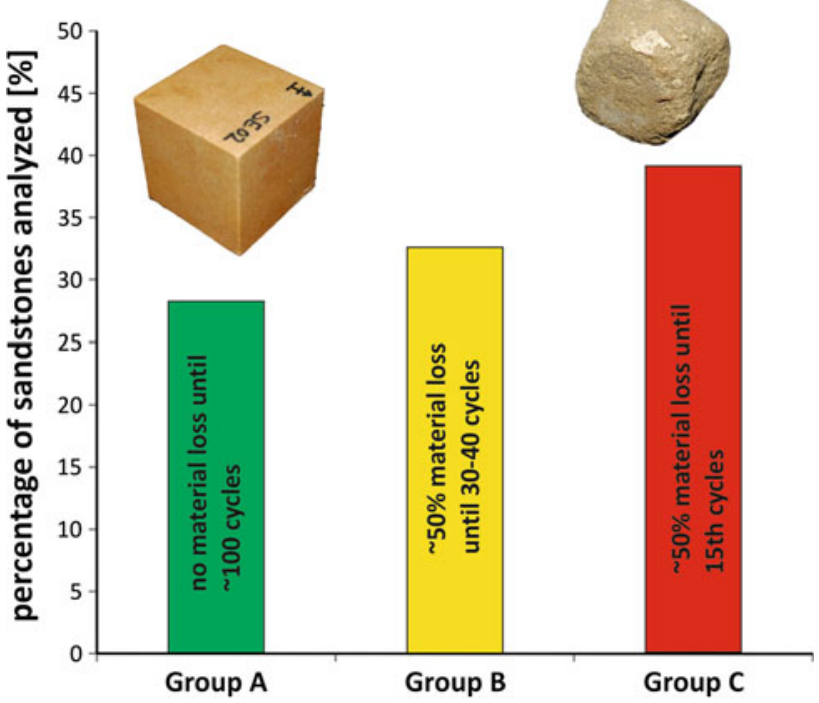

Fig. 17 Sandstones of different sandstones $[n=48$; David (2006), this study] with salt resistances classified into Group A (no material up to 100 cycles), Group B (50\% material loss up 30-40 cycles) and Group C (50\% material loss until the 15 th cycle)

The compressive strength shows interrelationships to the pore radii distribution, the type of grain contacts, the primary intergranular volume (minus cement porosity) as well as to the degree of alteration, amount of cementation and content of unstable lithic fragments. Furthermore, a wellexpressed interrelationship between the amount of mechanical stable grains and the compressive strength can be confirmed. Moreover, a high compressive strength is associated with a longer time and increasing depth of burial, which also correlates with a lower amount of porosity. After Füchtbauer (1967) and Houseknecht (1984), a negative relationship between grain size and volume of quartz cement exists. Regarding a stabilizing effect by quartz cementation on sandstones, also a positive correlation between grain size and strength should be observable. However, a relationship between average grain size and strength was not detected.

The amount, size, and geometry of the pores significantly affect the weathering resistance of a natural building stone, since they trigger the water balance (Fitzner and Snethlage 1982; Putnis et al. 1995; Putnis and Mauthe 2000; Ruedrich et al. 2011). As documented in this study, the properties such as capillary water absorption, water absorption under normal conditions and under vacuum, as well as the resulting saturation degree are closely related to the porosity characteristics of a given sandstone. The sorption depends significantly on the amount of micropores (Peschel 1983; Klopfer 1985; Siegesmund and Dürrast 2011). Moreover, the pore radii distribution defines the kind of water transport (Ruedrich and Siegesmund 2006; 

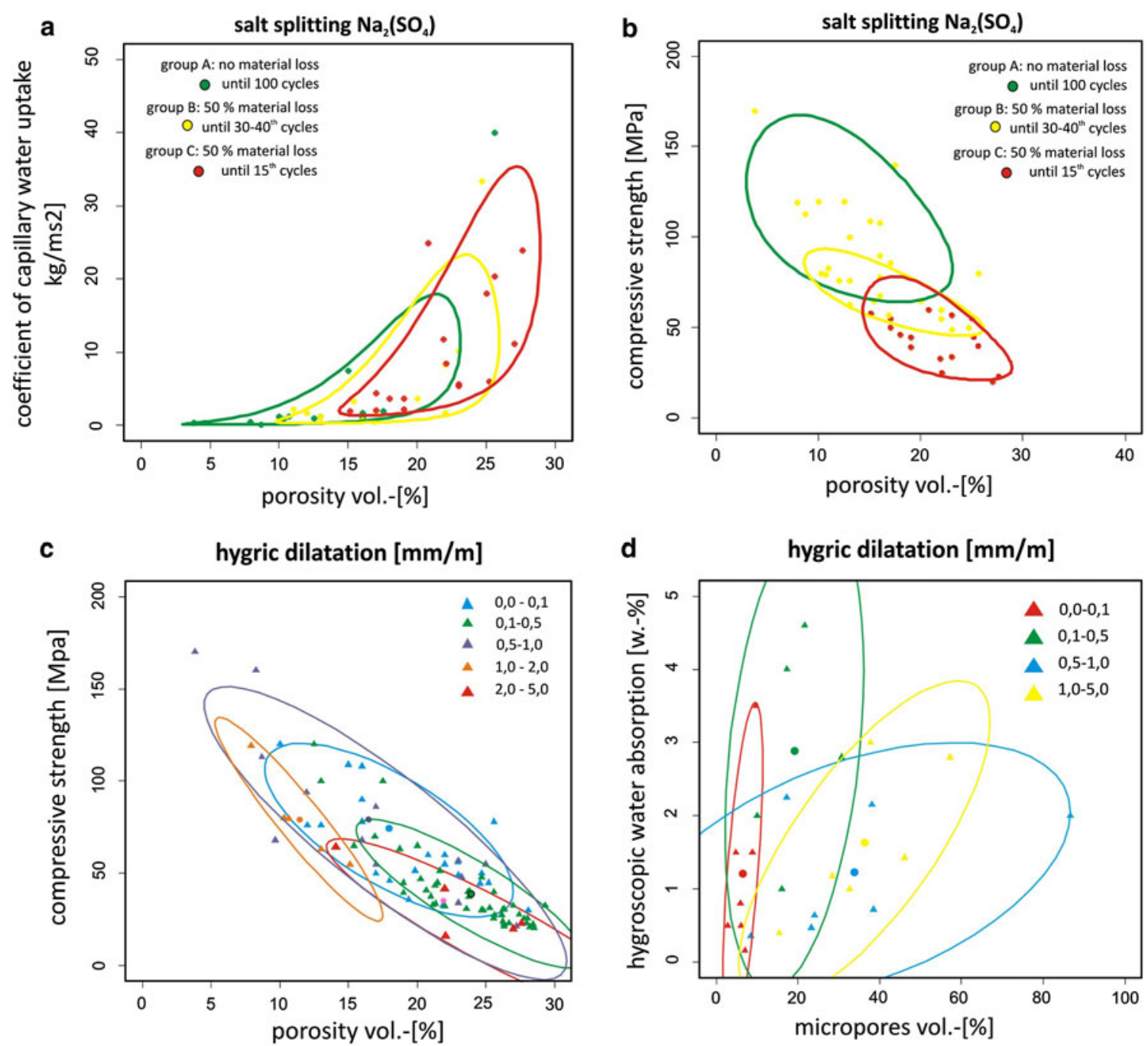

Fig. 18 Diagrams showing the interrelationships between selected petrophysical parameters and salt resistance: a coefficient of water absorption, porosity and groups of salt resistance $(n=48$; David 2006 and own), b compressive strength, porosity and salt resistance ( $n=48$; David 2006 and own samples), c compressive strength,

porosity and hygric dilatation (David 2006; Kirsten 2009; Holzwarth 1996 and own samples) and d sorption (weight increase at $100 \%$ rel. air humidity), content of micropores and hygric dilatation. Ellipsoids illustrate the $80 \%$ confidence regions

Siegesmund and Dürrast 2011) and, therefore, significantly influences weathering resistance of sandstones (Fitzner and Snethlage 1982).

Compressive strength, porosity and pore radii distribution can be defined as general key parameters for the prediction of salt resistance and hygric dilatation. However, these parameters are the result of the primary mineral composition (compositional maturity) and the diagenetic development (lithification; type and intensity of cementation; formation of secondary porosity) Stück et al. (2011). Based on these parameters, a model for the interpretation of the diagenetic development of the different sandstone types and their material properties will be discussed below. The goal of this model is to characterize the development of pore space geometry and to predict/estimate their possible weathering behaviour.

Diagenetic sequences in different sandstone types and the development of pore space geometry and compressive strength

Transport mechanisms and the physicochemical eogenetic conditions in the depositional milieu (water chemistry; intrastratal solution) of detrital grains are the basic parameters for the following diagenetic pathways during eogenetic alterations and finally trigger the material properties markedly. The initial porosity is fixed with deposition of the unconsolidated sediment, as expressed by the textural and compositional maturity. Houseknecht (1988) postulates an initial porosity for subarkosic wackes deposited in meandering river systems of $60 \%$, and for subarkoses from braided rivers with $40 \%$. Analyses of 
Fig. 19 Diagrams showing principal component analyses in dependency on a pore radii distribution, b lithotype (abbreviations: qtz quartz arenite, sublith. sublitharenites, lith. litharenites) and c additional properties like sorption, micropores, unstable lithic fragments and intergranular volume in interrelationship to different lithotypes. d Cluster analyses with clusters based on petrophysical properties of different sandstones. From the left to the right, the weathering resistance increases (for explanation see text; analyses include own data as well as data of Bartelsen (2008), David (2006), Kirsten (2009), Seidel (2004))
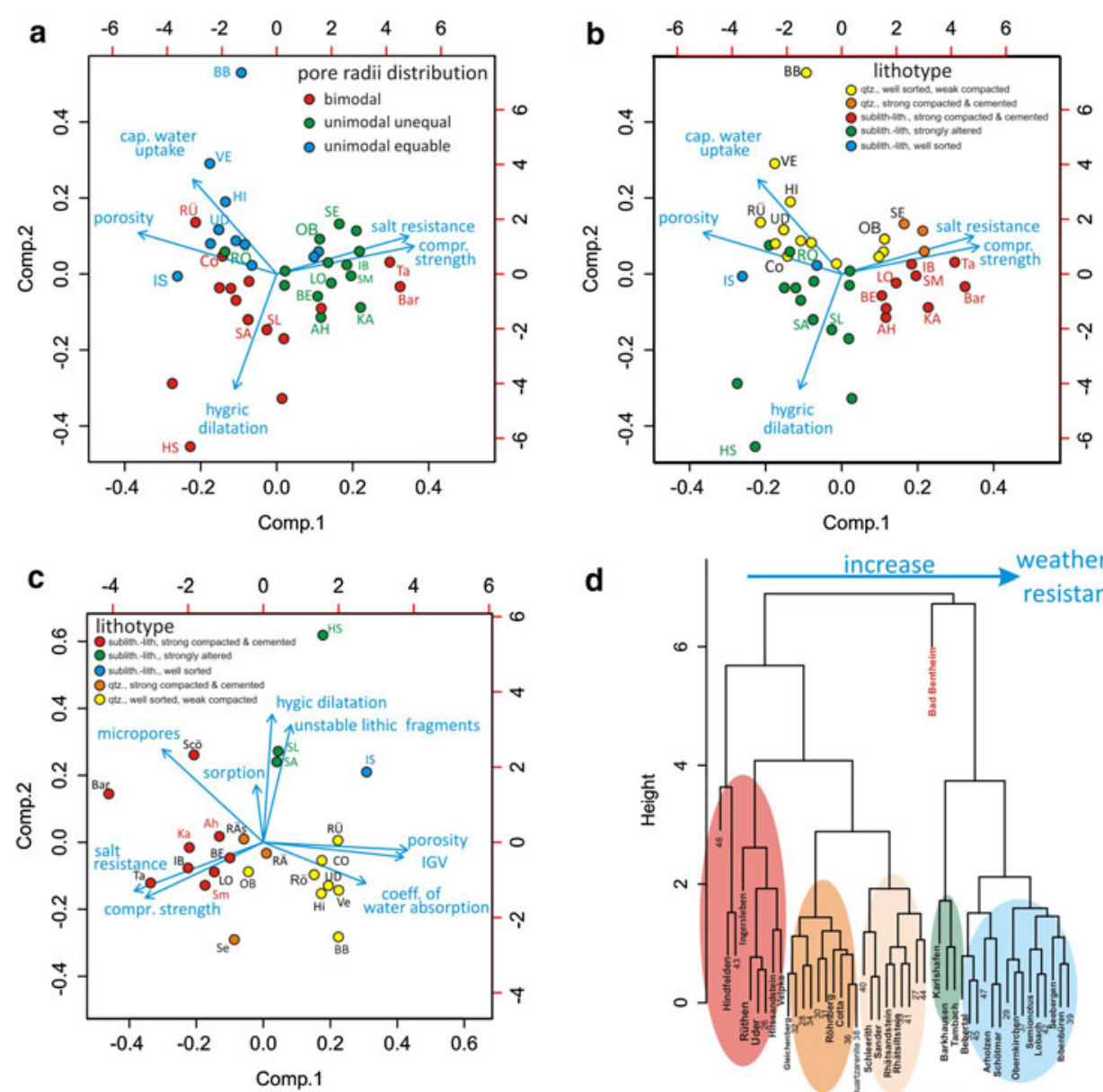

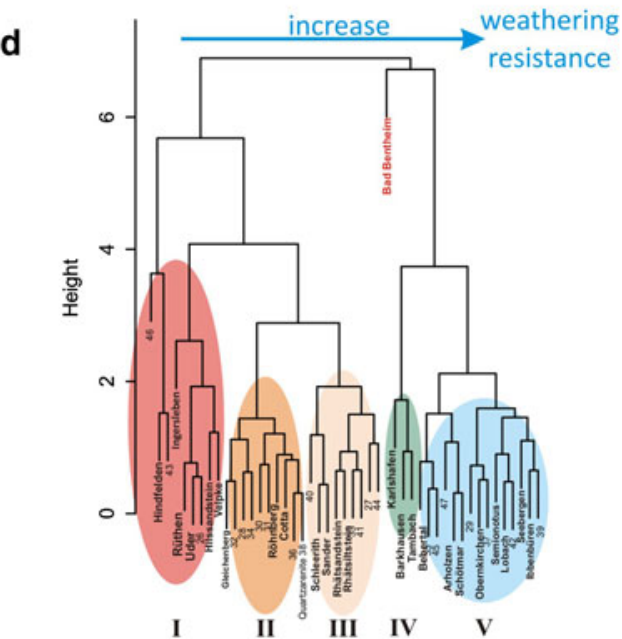

Table 4 Components and loadings of principal component analysis of Fig. 19a, b

\begin{tabular}{lclccc}
\hline & Comp. 1 & Comp. 2 & Comp. 3 & Comp. 4 & Comp. 5 \\
\hline $\begin{array}{l}\text { Loadings } \\
\text { Porosity }\end{array}$ & 0.57 & 0.23 & 0.14 & 0.03 & 0.02 \\
$\begin{array}{c}\text { Hygric } \\
\text { dilatation }\end{array}$ & -0.55 & 0.255 & & & \\
$\begin{array}{c}\text { Compressive } \\
\text { strength }\end{array}$ & 0.542 & 0.172 & -0.25 & -0.69 & 0.796 \\
$\begin{array}{c}\text { Cap. water } \\
\text { absorption }\end{array}$ & -0.33 & 0.586 & -0.61 & -0.11 & -0.41 \\
Salt resistance & 0.521 & 0.234 & -0.34 & 0.710 & 0.228 \\
\hline
\end{tabular}

The loadings are documented for each rock property

artificial grain mixtures of natural sands show that poorly sorted sands have a porosity of $27.9 \%$, weakly sorted sands $30.7 \%$, moderately sorted $34 \%$, well-sorted $39 \%$ and for very well-sorted sands $40.8 \%$ (Beard and Weyl 1973). These data are consistent with the data of sandstones analysed in the present study. Well-sorted quartz arenites show the highest intergranular pore volume of 25-30\%, whereas moderately sorted sandstones show a lower intergranular pore volume (15-20\%). However, where unstable lithic fragments are altered to pseudomatrix in sandstones, the intergranular volume and secondary porosity can increase greatly. After Schmidt and McDonald (2012), secondary porosity is also caused by mesogenetic leaching of carbonate minerals such as calcite, dolomite and siderite. Besides the primary composition, clay infiltration or Fe-oxide rims formed during eodiagenesis have a marked influence on the later grain overgrowth by silica (Cecil and Heald 1971) and the formation of special clay mineral cements. When clay rims observed are thick $(2-5 \mu \mathrm{m})$, quartz overgrowth is hindered. If $\mathrm{Fe}$-organic complexes are present during the mesodiagenetic burial stage, authigenic chlorite cement rims can be formed around grains. If $\mathrm{Fe}-$ organic complexes or other $\mathrm{Fe}$ phases are missing, illite cement rims are commonly formed (Surdam et al. 1989). Besides the influence of clay minerals on the later cementation, the content of clay minerals in general affects the acoustic velocities and also the compressive strength of sandstones (Kowallis et al. 1984; De Martine et al. 1976; Han et al. 1986). In general, increasing 
clay contents result in decreasing ultrasonic velocities independent of the degree of consolidation.

Grains can be differentiated into mechanical and chemically stable/unstable components (McBride 1963, Fig. 20). Therefore, during compaction under burial conditions, the content of ductile grains plays an important role for the further development of the pore space. Large differences in the porosity during burial diagenesis are generated by mechanical and chemical compaction (Surdam et al. 1989; Hartmann et al. 2000). In comparison to feldspathic and lithic sandstones, quartz arenites require deeper burial conditions for compaction (porosity decrease) to the same degree (Fig. 21, Dickinson 1985). Regression analysis between compressive strength and amount of porosity shows that the content of unstable lithic fragments markedly influences the data documented in the strengthporosity plot. This confirms that the higher the content of unstable lithic fragments, the lower is the grain contact between stable grains probable. Moreover, the type of grain contacts has an influence on compressive strength. Sandstones with predominantly concave-convex and sutured grain contacts exhibit a higher compressive strength than sandstones with pointed and elongated grain contacts. Compressive strength also varies within the groups of grain contact due to the different kinds and intensity of cementation. In addition, the kind of unstable lithic fragments is also important for later cementation. If volcanic detritus is present, hydration reactions are favoured and the formation of authigenic feldspar is common. In contrast, abundant chert fragments can inhibit quartz cementation and thus preserve porosity (Surdam et al. 1989).

Furthermore, our results also show that porosity and compressive strength are dependent on the burial time. As Scherer (1987), Waples (2002) and Koch and Sobott (2008) documented, sandstones of the same sorting and the same quartz content which were buried into the same depth can show different amounts of porosity that is related to the different time of burial.

These interrelationships are also reflected by all the data of sandstones recently analysed as schematically summarized in Fig. 22. Pure quartz arenites are commonly well sorted (high maturity), have a primary porosity of $39-40 \%$, a unimodal pore radii distribution and reveal capillary pores of $0.1-10 \mu \mathrm{m}$ radius. During the closer packing of grains, pressure solution starts at the point contacts (chemical compaction) and porosity further decreases. Depending on a possible infiltration of clay during eogenesis or not, a quartz dissolution/cementation reaction takes place. If there is no clay infiltration, the sandstone may be more intensively compacted and a high contact thickness (Füchtbauer 1988) occurs, which is defined by the grain contact length in the entire sandstone and depends on the type of grain contact. The potential for

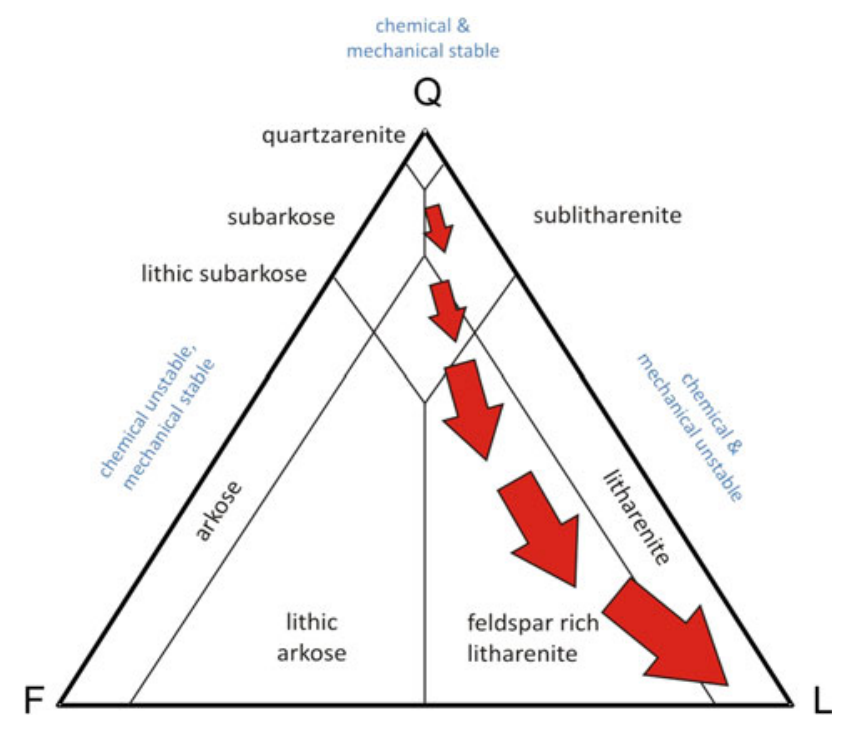

Fig. 20 Simplified illustration of relationship between lithology ( $Q$ quartz, $F$ feldspar, $L$ lithoclast), mechanical properties during compaction and pore space development. Arrows show trend of porosity decrease through compaction and decrease of chemical and mechanical stability with increasing amount of unstable lithic fragments and resulting weathering resistance (Modified after McBride 1963)

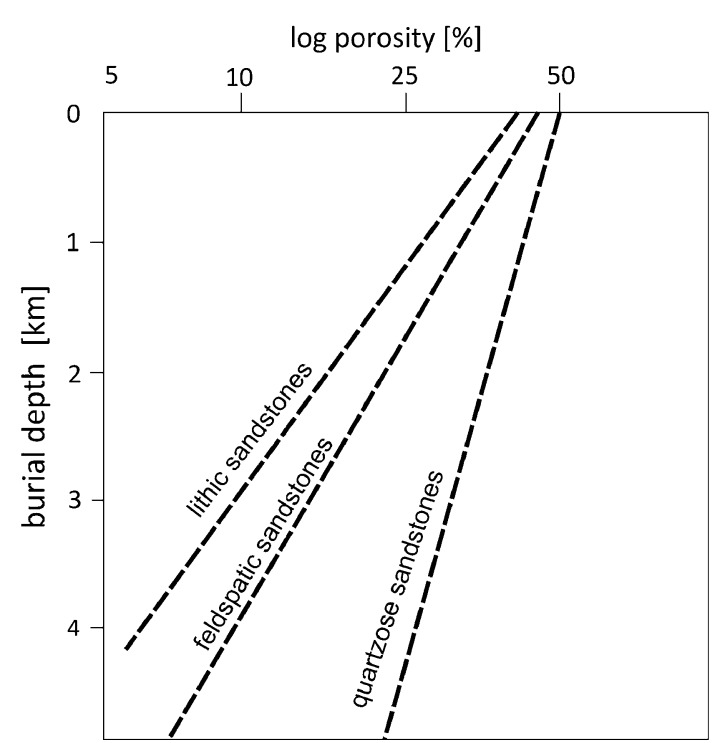

Fig. 21 Porosity relationship for sandstones of different composition. Modified after Dickinson (1985)

quartz pressure solution is given in clay-bearing sandstones since $\mathrm{K}_{2} \mathrm{O}$ increases the $\mathrm{pH}$ value. This promotes the solution of quartz (Füchtbauer 1974) and therefore also influences the porosity modification. The pore radii distribution commonly reveals the same unimodal equal distribution as in the beginning diagenetic stages. Nevertheless, the average pore size becomes smaller because of the reduction of larger gusset pores by quartz cementation. The pore radii distribution of sandstones, which are much more 


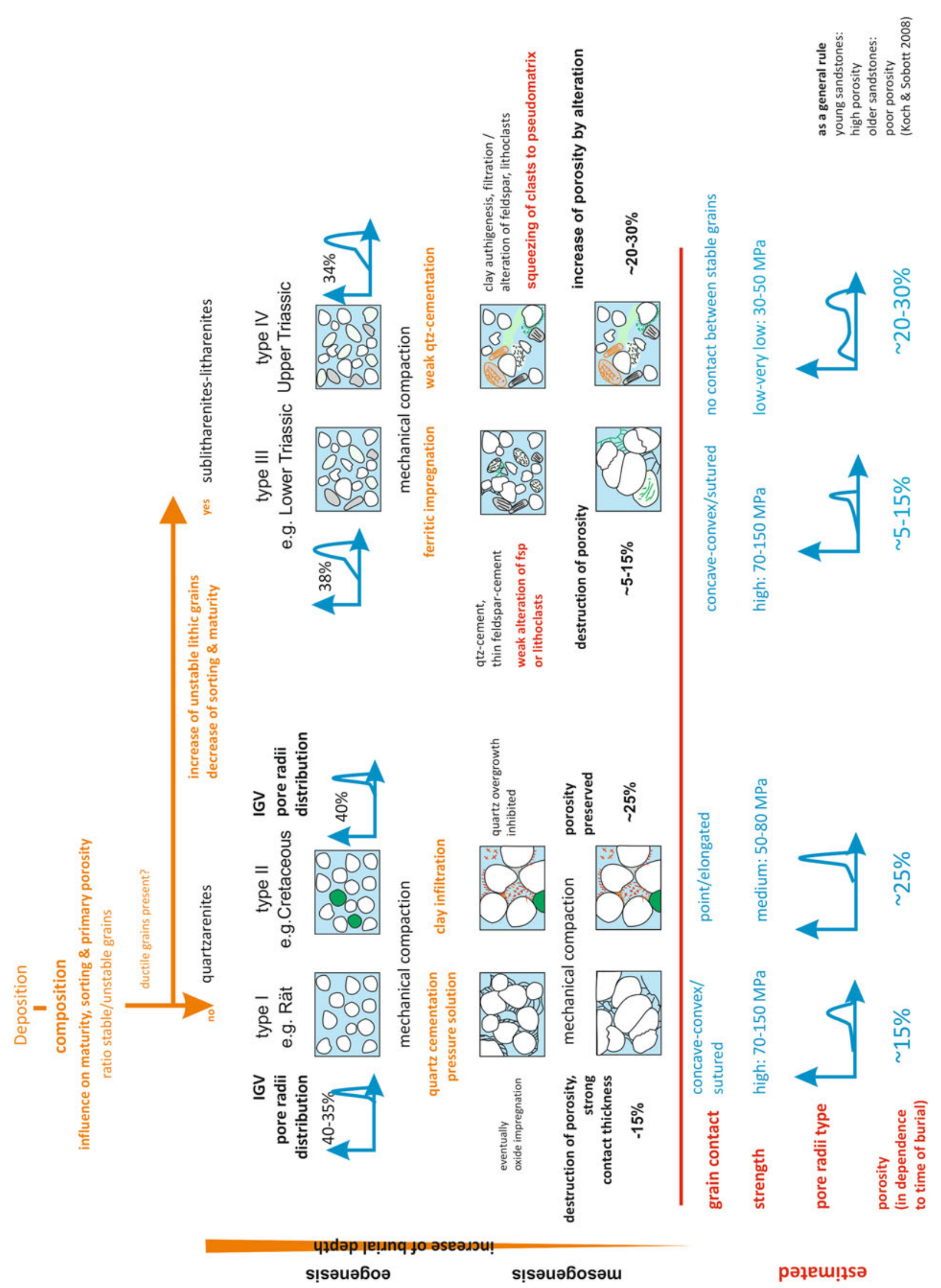


4Fig. 22 Development of pore space and compressive strength of different sandstone types. After deposition, the primary composition and sorting rule the (primary) porosity (intergranular volume $=\mathrm{IGV}$ ) and the pore radii distribution. Therefore, mature quartz arenites show higher porosity than more immature sublitharenites-litharenites. This porosity is modified through clay infiltration, alteration, cementation and compaction. During eogenesis, clay infiltration can occur that creates micropores and prohibits quartz overgrowths during later mesogenesis, which is why the porosity is preserved. Compaction and cementation decrease the porosity during further diagenesis, and thus contact thickness can increase, which finally leads to higher strength. Estimated for each lithotype are grain contact, strength, pore radii type and porosity. Since the controlling parameters during diagenesis can vary, the material properties also have to be interpreted as flowing transitions

strongly compacted, can shift to unimodal unequal and smaller capillary pores. In the same way, the water absorption increases due to the presence of more capillary pores.

These interrelationships are observable in Upper Triassic (Rhät; e.g. RÖ, SE, Tables 1, 3) and Cretaceous (e.g. BB, RÜ, OB, VE, Tables 1, 3) quartz arenites investigated in this study. Dependent on burial time and sorting, the porosity is between $\sim 15$ and $30 \%$. Sandstones belonging to the Upper Triassic exhibit a porosity of around 15-20\% (e.g. SE, Tables 1, 3), whereas younger sandstones belonging to the Cretaceous show a porosity ranging from 25 to $30 \%$. According to Blöcher et al. (2007), a homogeneous pore size distribution results in a higher compressive strength. This can be transferred to the quartz arenites that show a unimodal equable pore radii distribution. Because no unstable lithic fragments are present, these two sandstone types of Upper Triassic and Cretaceous show a medium to high compressive strength (70-150 MPa). Within the glauconite-bearing Cretaceous sandstones, furthermore a weak negative relationship to compressive strength is observable (e.g. HI, CO, RÜ). Further impact on strength can have a clayey matrix, which distinctly decreases the rock strength like in case of sandstone Cotta. Simultaneously, if early clay infiltration took place and clay rims are formed around detrital grains, quartz overgrowths are inhibited and micropores occur in increasing amounts, which both clearly decreases the compressive strength (e.g. RÖ, Tables 1, 3). Here, the kind of infiltrated clay minerals are also important: While porefilling kaolinite reduces porosity and has little effect on permeability, lining the pores with illite has little effect on porosity, but permeability becomes considerably reduced by blocking pore throats (Stalder 1973; Tucker 2001). According to Stonecipher et al. (1984), low permeability promotes cementation. In contrast, in sandstones with high permeability, solutions do not remain in pore spaces long enough to build local concentration that promotes precipitation of cement. However, in both cases the pore size distribution through clay minerals is modified from unimodal equal to unimodal unequal. This results in a lower strength (50-80 MPa), since the heterogeneity of pore size distribution increases and the porosity $(\sim 25 \%)$ is preserved by prohibited cementation of silica or calcite by the presence of clay minerals. Because of the effect of clay mineral cements, which can be compared to clay matrix and/or pseudomatrix, the grain contacts of detrital grains are predominantly point contacts.

When the content of unstable lithic fragments and/or feldspar increases, such as in subarkoses, sublitharenites and litharenites, the development of pore space and compressive strength is independent of each other (Fig. 22). In these sandstones, the compositional and textural maturity is much lower than in quartz arenites. Furthermore, the ratio between textural to compositional maturities also significantly influences the quality of the latter natural building stone. The so-called Weser sandstones (Lower Triassic; Tables 1, 3: samples KA, LO, AH) are examples of this sandstone type. The primary porosity of the moderate- to well-sorted sandstone is $34-39 \%$. The pore radii distribution is unimodal unequal. During eogenesis, haematite impregnation occurs. With advancing burial compaction, feldspar alteration and quartz dissolution commonly takes place. Subsequent to quartz cementation, authigenic clay minerals are formed due to the alteration of feldspars or unstable lithic fragments and also carbonate cementation occurs. The intergranular pore space decreases markedly due to compaction and cementation. The alteration of feldspar and unstable lithic fragments create a small amount of micropores. The final pore radii distribution is unimodal unequal and the compressive strength is dependent on the degree of alteration and cementation that is medium to high (70-150 MPa). The coefficient of capillary water absorption is low $\left(\sim 0-5 \mathrm{~kg} / \mathrm{ms}^{2-}\right)$, because only a very small amount of capillary pores is developed and porosity is mostly low. Sandstones of similar composition but longer burial history such as the Carboniferous and Permian sandstones (Tables 1, 3; samples IB, TA, BE) show a similar pore size distribution, but markedly lower porosity (up to $10 \%$ ) and a higher compressive strength (70-160 MPa). Due to the lower porosity, also the water absorption is weakly pronounced.

Sublitharenites and litharenites of the Upper Triassic Schilfsandstein and Lettenkohlenkeuper show very low textural and compositional maturity (e.g. HS, IS, SA, SL; Tables 1, 3). The grains are angular to subangular and unstable components are moderately altered. The primary porosity also ranges from 34 to $39 \%$, because the rock is moderately well sorted. However, the textural maturity is characterized by contents of squeezed altered unstable lithic fragments to pseudomatrix, which distinctly decreases the textural maturity of these sandstones. After 
deposition, porosity decreases through compaction and silica cementation. Partially, organic fragments parallel to bedding destabilize the fabric (e.g. HS, IS). The alteration of (volcanic) clasts to clay minerals and clayey matrix tends to be squeezed between more rigid grains (pseudomatrix), even during the initial stages of diagenesis at shallow burial. This also prohibits a free circulation of fluids and leads to restricted cementation. Porosity decreases through further compaction and the content of micropores increases greatly because of the altered unstable lithic fragments. This finally leads to sandstone with a low compressive strength, because in this rock with heterogenous pore radii distribution a stable grain framework does not exist anymore. The bimodal pore radii distribution supports high water absorption. The maximum in capillary pores promotes the capillary water absorption and the maximum in micropores the sorption. Statistical data of the different lithologies, fabric properties and type of grain contact, compressive strength, porosity and pore radii distribution are documented and summarized schematically in Fig. 22.

Considering the lateral change of sorting, an increase of textural maturity and decrease of grain size with increasing transport distance from the source area should be developed for each sandstone. Accordingly, a lateral change of primary composition due to the content of unstable grains, sorting and primary porosity should be developed. However, the increase of maturity has to be regarded under very local conditions with alternating directions and cannot be transferred by only considering the original source area of the sediment. For example, the Keuper sandstones of the Burgsandstein (Vindelizian Keuper) should show an increase of compositional and textural maturity from SE to the NW direction. However, these sandstones were predominantly deposited in channels of alluvial fans, and therefore they show a highly variable maturity. Thus, general statements on lateral development of material properties are not possible in the present study.

\section{Weathering behaviour in dependence to composition}

Regression analysis and principal component analyses allow the prediction of pore space, compressive strength and water absorption for sandstones of differing lithology. Weathering behaviour can therefore be estimated because these parameters show linear correlations to the petrophysical properties. Although porosity is a key for characterizing the weathering behaviour of the sandstones, the same amounts of porosity can lead to different resistances against salt splitting or hygric dilatation. The results of the salt splitting tests agree with other studies on German sandstones (Snethlage and Wendler 1997; Fitzner and Snethlage 1982; Zehnder and Arnold 1989; Ruedrich et al.
2006), where it was documented that sandstones with a high amount of very small capillary pores and micropores are highly sensitive to salt splitting. According to Snethlage and Wendler (1997), the pore space characteristics control the solution transport and in consequence also the distribution and amount of salt in the rock. Thus, a correlation between the stability against salt splitting, pore size distributions and lithotype is well expressed. Furthermore, the compressive strength is also important for the interpretation of stability against salt splitting, because the rock has to withstand increasing crystallization pressures of the salt (Goudie and Vlies 1997; Scherer 1999), which should not surmount the degree of internal stability indicated by the compressive strength. Accordingly, highly mature quartz arenites, which are weakly compacted (high porosity), exhibiting a high amount of micropores due to the infiltration of clay minerals, have a low-medium compressive strength (e.g. Rö, Tables 1, 3) and show only a moderate resistance to salt splitting (Group B-C). The Bad Bentheim sandstone surprisingly is a rock with a very high resistance to salt splitting and hygric dilatation, although the rock shows high porosity, medium compressive strength, high capillary water absorption and swellable clay minerals (Tables 1, 3). This confirms the special position of sandstone Bad Bentheim, illustrated also by cluster analyses (Fig. 18d). The pore radii distribution with only clear maxima in large capillary pores probably does not induce any stress during salt crystallization, since crystal growth can take place within the free pore space without any resistance. The homogeneous pore space could be responsible for the medium strength as mentioned above (Blöcher et al. 2007).

Highly compacted and cemented quartz arenites without the infiltration of clay predominantly exhibit a very high resistance against salt splitting, because the distribution of pore radii indicates just a very low amount of micropores and also only low porosity (e.g. SE, Tables 1, 3). Sandstones enriched in unstable feldspars and lithic fragments, which are highly compacted and cemented, commonly show a high compressive strength, low porosity and favourable pore radii distribution (e.g. unimodal unequal), and therefore are also resistant against salt splitting. Sublitharenites and litharenites with common altered rock fragments and pseudomatrix show the lowest resistance against salt splitting. The pore radii distribution is characterized by a large amount of micropores caused by the alteration of unstable lithic fragments (partially squeezed to pseudomatrix) and a compressive strength which is too low to withstand the increasing internal pressure by salt crystallization. The lowest salt resistance of the sandstones analysed are found, e.g. in the Ingersleben and Hindfelden sandstones of the Upper Triassic (Schilfsandstein, Lettenkohlenkeuper) (Tables 1, 3). 
Different reasons are discussed for the process of hygric dilatation. After De La Calle and Suquet (1988), Weiss et al. (2004), Dixon and Weed (1989) and Moore and Reynolds (1989), the dilatation is mainly caused by the presence of expending clay (intracrystalline swelling). Also discussed is the model of disjoining pressure, comparable to the intercrystalline swelling caused by interaction within the electrical double layer at the mineral surfaces (Morales Demarco et al. 2007; Ruedrich et al. 2011). This process is limited on very small pore channels. The analyses of hygric dilatation in the present study confirm that the amount of micropores triggers the weathering processes markedly, which confirms a relationship to the presence of clay minerals, since they create these micropores. Experiments on clay mixtures prove that swelling clay minerals begin to expand at a relative air humidity of $45 \%$ (Xiang and Czurda 1995). However, many sandstones show a volume increase already at $15 \%$ air humidity (Morales Demarco et al. 2007; Ruedrich et al. 2011). Because swelling clay minerals (montmorillonite; mixed layers) only occur in very minor amounts in the sandstones analysed, other parameters might also be responsible for the hygric dilatation measured. This is underlined in the test with the quartz arenites (e.g. Cretaceous; Bad Bentheim sandstone). Both strongly compacted as well as poorly compacted quartz arenites rarely show hygric dilatation (mean: $0.05 \mathrm{~mm} / \mathrm{m}$ ), although they exhibit swellable clay minerals (e.g. BB, Tables 1, 3). Probably also the position of the clay minerals and micropores within the sandstone is important for hygric dilatation. In contrast, sandstones exhibiting bimodal pore radii distribution and high alteration of unstable lithic fragments/feldspars or pseudomatrix show the greatest hygric dilatation. Maybe the position of clay in the shape of huge altered lithic fragments promotes water retention behaviour. Eventually also permeability affects the hygric dilatation, since sandstones with high values of hygric expansion exhibit low permeability caused by the content of altered unstable lithic fragments. Sandstones of this type belong to sublitharenites-litharenites of Schilfsandstein and Lettenkohlenkeuper (Upper Triassic). The highest value of hygric dilatation was measured in the Hindfelden sandstone (Upper Triassic, Schilfsandstein). This extraordinary value probably can be traced back to the combined effects of swellable clay minerals and the bimodal pore radii distribution with the high amount of micropores, caused by the presence of altered lithic fragments. Also, heavily compacted and cemented Lower Triassic sublitharenites with unimodal unequal pore radii distribution exhibit distinct hygric dilatation (e.g. KA, AH, Tables 1, 3). Therefore, we assume that hygric expansion can be connected with the interaction of the presence of micropores, the type and spatial arrangement of clay minerals on surfaces of detrital grains and on the content of altered unstable lithic fragments (see also discussion in Ruedrich et al. 2011).

\section{Summary—quality catalogue for sandstones}

The results of the present study indicate that statistical analyses of a very large number of sandstones can be used to predict the material and weathering behaviour of these natural stones. Multiple parameters affect the material properties of these heterogeneous rocks. The possible problems of compiling a data set from many different sources also have to be kept in mind. Furthermore, petrographical and petrophysical parameters can change locally within each individual rock and, therefore, the material properties can also vary considerably.

Linear interrelationships between the basic parameters of porosity, pore radii distribution and compressive strength can be established for each sandstone lithotype defined. Because these parameters correlate with the weathering properties, a prediction for salt resistance and hygric dilatation can be made for each sandstone type. Material properties are dependent on different magnitudes of influences. Thus, the transition between the different lithotypes is fluent and, therefore, the weathering behaviour is common. Figure 23 schematically summarizes the petrographical and petrophysical properties as well as their resistance against salt splitting and hygric dilatation. In general, the construction suitability is determined by different classes from the combination of the salt resistance and hygric dilatation results, in which all other parameters are incorporated with a very large confidence.

In the present study, two types of quartz arenites and two types of sublitharenites-litharenites as natural building stone could be distinguished:

- High mature quartz arenites, which are strongly compacted and cemented with little early infiltrated clay minerals and mainly sutured concave-convex grain contact. They exhibit a compressive strength between 70 and $150 \mathrm{MPa}$, a porosity up to $15 \%$ and a unimodal unequal pore radii distribution. Due to the low hygric dilation and high salt resistance (Group A), they can be defined as weathering resistant.

- Quartz arenites, which are weakly compacted and cemented, with point-elongated grain contact, partially containing glauconite grains and high content of early infiltrated clay minerals. The compressive strength is between 50 and $80 \mathrm{MPa}$, the porosity amounts to $\sim 25 \%$ and the pore radii distribution is unimodal equal. Due to the low hygric dilatation but medium-low salt resistance, the rock can be defined as moderatewell weathering resistant. 


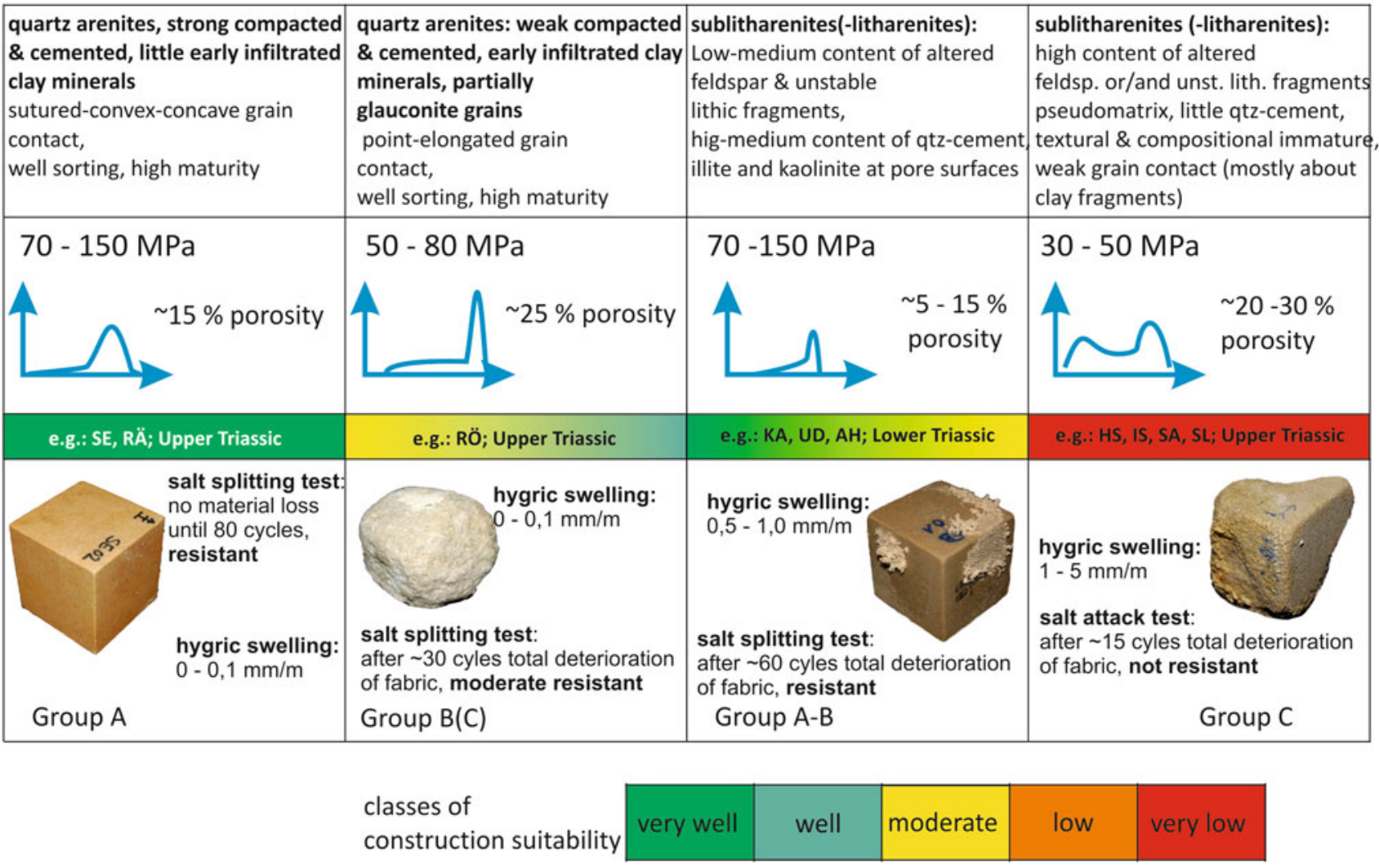

Fig. 23 Illustration summarizing a quality catalogue for sandstones. From left to right, the textural and compositional maturity increases. Coloured bars indicate the classes of construction suitability. In general, four different sandstone types with characteristic fabric types were classified material parameter such as porosity and compressive strength, as well as the weathering properties characterized by salt

- Sublitharenites (-litharenites) with a low-medium content of altered unstable lithic rock fragments and feldspars, high-medium content of quartz cement as well as illite and/or kaolinite at grain surfaces. The compressive strength is $70-150 \mathrm{MPa}$ and medium to high, the porosity is between 5 and $15 \%$ and the pore radii distribution unimodal unequal. The salt resistance belongs to group $\mathrm{A}-\mathrm{B}$ and hygric swelling amounts to $0.5-1.0 \mathrm{~mm} / \mathrm{m}$.

- Sublitharenites (-litharenites) with high content of altered unstable lithic fragments and/or feldspars, little quartz cement and weak grain contact between the few stable detrital grains. The lithic fragments are mostly squeezed to pseudomatrix. The compressive strength is $30-50 \mathrm{MPa}$ and very low and the porosity is $20-30 \%$ and very high. Due to the high values of hygric dilatation and the low salt resistance, this sandstone type can be defined as not weathering resistant. resistance and hygric swelling, are also determined. Salt resistance is divided into three groups: Group A (no material loss up to 100 cycles), Group B (50\% material loss up 30-40 cycles), and Group C (50\% material loss up to 15 cycles). The transition between each lithotype is interpreted as being fluent

Despite the material properties of dimension sandstones discussed in this paper, the evaluation of a suitable replacement stone must additionally take into account the compatibility of a replacement stone to the adjacent rocks. For example, moisture properties such as capillary and sorptive water absorption and water saturation of the original and replacement rock should be of the same magnitude. A case study considering this interaction of original and replaced dimension stones is presented by Graue et al. (2011) for the Cologne cathedral.

Acknowledgments We would like to thank the Deutsche Bundesstiftung Umwelt for supporting the long-term $\mathrm{PhD}$ fellowship for H. Stück (AZ 20008/997). Furthermore, gratitude also goes to Dr. O. Nenadic and Dr. J. Schuhmacher for the constructively support of statistics, Dr. R. Dohrmann und Dr. S. Kaufhold for analysing the clay mineral compositions (BGR), and Christian Gross for editing the English. Special thanks go to Dr. J. Ruedrich ${ }^{\dagger}$ for his help and unreserved discussions on all experimental results. 
Open Access This article is distributed under the terms of the Creative Commons Attribution License which permits any use, distribution, and reproduction in any medium, provided the original author(s) and the source are credited.

\section{References}

Aigner T, Bachmann G (1992) Sequence stratigraphic framework of the German Triassic. Sedimentary Geology 80:115-135

Bartelsen T (2008) Gefügeabhängiges Verwitterungsverhalten tonmineralführender Sandsteine durch hygrothermisch induzierte Dehnungsprozesse, unpublished diploma thesis, Göttingen

Beard DC, Weyl PK (1973) Influence of texture on porosity and permeability of unconsolidated sand. AAPG Bull 57:349-369

Beutler G, Schubert J (1987) Fazielle Entwicklung des Mittleren Lettenkeuper im Thüringer Becken. Z Geol Wiss 15:475-484

Blöcher G, Bruhn D, Zimmermann G, McDermott C, Huenges E (2007) Investigation of the undrained poroelastic response of sandstones to confining pressure via laboratory experiment, numerical simulation and analytical calculation. Geological Society Special Publications, London

Burley SD, Kantorowicz JD, Waugh B (1985) Clastic diagenesis. In: Brenchley PJ, Williams BJP (eds) Sedimentology: recent developments and applied aspects. Special publication 18. Geological Society of London, Bath, pp 89-226

Cecil CB, Heald MT (1971) Experimental investigation of the effects of grain coatings on quartz overgrowth. J Sediment Petrol 41:582-584

Chitsazian AH (1985) Beziehungen zwischen dem Mineralbestand, Gefüge und technologischen Eigenschaften der Niedersächsischen „Wealden“-Sandsteine (Unterkreide)-Mitteilungen aus dem Geologischen Institut Hannover, Diss

Choquette PW, Pray LC (1970) Geological nomenclature and classification of porosity in sedimentary carbonates. Am Assoc Petrol Geol Bull 54:207-250

David C (2006) Buntsandstein- Bausandstein, Marburger Bausandstein unter der Lupe. Zeitschrift der Marburger Geowissenschaftlichen Vereinigung e.V., 3, Marburg

De La Calle C, Suquet H (1988) Vermiculite. In: Bailey SW (ed.) Hydrous phyllosilicates. Reviews in Mineralogy. Mineralogical Society of America 19:455-496

De Martine DC, Beard D, Danburg JS, Robinson JH (1976) Variation of seismic velocities in sandstones and limestones with lithology and pore fluid at simulated in situ conditions: Proceedings of the EGPC exploration seminar, Cairo

Dickinson WR (1985) Interpreting provenance relations from detrital modes of sandstones. In: Zuffa GG (ed) Provenance of arenites. Reidel, Dordrecht, pp 333-361

Dixon JB, Weed SB (1989) Minerals in soil environments. 2nd edition Soil Science Society of America

Dohrmann CF, Kühn I (2009) Angewandte Statistik für die biologischen Wissenschaften. Helmholtz Zentrum für Umweltforschung-UFZ

Fitzner B (1970) Die Prüfung der Frostbeständigkeit von Naturbausteinen. Aachen, Diss

Fitzner B (1988) Untersuchung der Zusammenhänge zwischen dem Hohlraumgefüge von Natursteinen und physikalischen Verwitterungsvorgängen. Mitt. Ing.-u.Hydrogeologie, 29, Aachen

Fitzner B, Snethlage R (1982) Einfluß der Porenradienverteilung auf das Verwitterungs-verhalten ausgewählter Sandsteine. Bautenschutz und Bausanierung 3:97-103

Füchtbauer H (1967) Der Einfluss des Ablagerungsmilieus auf die Sandsteindiagenese im Mittleren Buntsandstein. Sediment Geol $1: 159-179$
Füchtbauer H (1974) Zur Diagenese fluviatiler Sandsteine. Geol Rundsch 63(3):904-925

Füchtbauer H (1988) Sedimente und Sedimentgesteine. 4. Auflage, 1141 S., Stuttgart (Schweizerbart)

Gilbert CM (1954) Sedimentary rocks, p.251-384 in Williams, H., Turner, F.J. and Gilbert, C.M. Petrography: San Francisco, W.H. Freeman \& Co., 406 p.

Goudie A, Vlies H (1997) Salt weathering hazards. Wiley, Hoboken

Graue B, Siegesmund S, Middendorf B (2011) Quality assessment of replacement stones for the Cologne Cathedral: mineralogical and petrophysical requirements. Environ Earth Sci 63(7-8):1799-1822

Grimm WD (1990) Bildatlas wichtiger Denkmalgesteine der Bundesrepublik Deutschland. Bayrisches Landesamt für Denkmalpflege, 50, München

Han D, Nur A, Morgan D (1986) Effect of porosity and clay content of wave velocities in sandstones. Geophysics 51(11):2093-2107

Hartmann DJ., Beaumont EA, Coalson E (2000) Predicting sandstone reservoir system quality and example of petrophysical evaluation. Predicting reservoir system quality and performance. In: Hartmann DJ, Beaumont EA (eds) Exploring for oil and gas traps, Beaumont EA, Foster NH (eds) Treatise of petroleum geology, handbook of petroleum geology, 1999

Hayes JB (1984) Sandstone porosity evolution. Short course notes, AAPG, Sandstone diagenesis School

Holzwarth D (1996) Werksandsteine der Region Vorderpfalz (westlicher Grabenrand des Obberheingrabens) und ihre petrographischen sowie geotechnischen Eigenschaften. Diss, Mainz

Houseknecht DW (1984) Influence of grain size and temperature in intergranular pressure solution, quartz cementation, and porosity in a quartzose sandstone. J sediment petrol 54(2):348-361

Houseknecht DW (1987) Assessing the relative importance of compaction processes and cementation to reduction of porosity in sandstones. Am Assoc Petroleum Geol Bull 71(6):642-663

Houseknecht DW (1988) Intergranular pressure solution in four quartzose sandstones. J Sed Petrology 58:228-246

Houseknecht DW, Pittman ED (eds) (1992) Origin, diagenesis \& Petrophysics of Clay Minerals in Sandstones. Special Publication 47. Society of Sedimentary Geologists, Tulsa

Katzung G (1975) Tektonik, Klima und Sedimentation in der Mitteleuropäischen Saxon-Senke und in angrenzenden Gebieten. Z Geol Wiss 3(11):1453-1472

Kirsten H (2009) Herkunft, Eigenschaften und Konservierungsmöglichkeiten von Lettenkeuper- und Schilfsandsteinen an Baudenkmalen in Thüringen. Diss, Weimar

Klopfer H (1985) Feuchte. In: Lutz et al.: Lehrbuch der Bauphysik. Teubner Verlag, Stuttgart, pp 265-434

Koch R, Sobott R (2008) Sandsteine: Entstehung, Eigenschaften, Verwitterung, Konservierung, Restaurierung. In: Siegesmund, Snethlage (eds) Schriftenreihe der Deutschen Gesellschaft für Geowissenschaften, vol 59, pp 145-174

Koch R, Baier A, Lorenz H, Fritsch A (2003) Sandsteine des Keupers als Naturwerksteine in und um Nürnberg (Exkursion B am 22. April 2003). Jber Mitt oberrhein geol Ver NF 85:45-64

Kowallis B, Jones LEA, Wang HF (1984) Velocity-porosity-clay content: systematics of poorly consolidated sandstones. J Geophys Res 89:10355-10364

Massallam K (1973) Sedimentologie, Petrographie und Diagenese der Valendis Sandsteine Erdölfeld Leiferde-Gifhorner Trog (Unterkreide - NW-Deutschland). Diss, Univ. Hamburg

McBride EF (1963) A classification of common sandstones. J Sediment Petrol 33(3):664-669

Moore DM, Reynolds RC Jr (1989) X-ray diffraction and the identification and analysis of clay minerals. Oxford University Press, Oxford

Morad S, Ketzer JM, De Ros LF (2000) Spatial and temporal distribution of diagenetic alterations in siliclastic rocks: 
implications for mass transfer in sedimentary basins. Sedimentology Suppl 1:95-120

Morales Demarco M, Jahns E, Ruedrich J, Oyhantacabal P, Siegesmund S (2007) The impact on partial water saturation in rock strength: an experimental study on sandstones. Zeitschrift der Deutschen Gesellschaft für Geowissenschaften 158:869-882

Mosch S, Siegesmund S (2007) Statistisches Verhalten petrophysikalischer und technischer Eigenschaften von Naturwerksteinen. Z Dtsch Geol Ges 158/4:821-868

Müller H, Luckert J, Röper D (2002) Sandsteinverwitterung durch bauschädliche Salze-Ergebnisse der Säulensanierung des Belvedere auf dem Pfingstberg/Potsdam-Brandenburgische Geowissenschaftliche Beiträge 9:1-15; Kleinmachnow

Paul J (1982) Der Untere Buntsandstein des Germanischen Beckens. Geol Rundsch 71:795-811

Paul J, Wemmer K, Ahrend H (2008) Provenance of Triassic siliciclastic sediments in Central Europe. Z dt geol Ges 159:641-650

Peschel A (1983) Natursteine. VEB Deutscher Verlag für Grundstoffindustrie, Leipzig

Pettijohn FJ (1975) Sedimentary rocks. Harpers u. Brothers, New York

Pettijohn FJ, Potter PE, Siever R (1987) Sand and sandstone. Springer, New York

Plein E (1993) Bemerkungen zum Ablauf der paläogeographischen Entwicklung im Stephan und Rotliegend des Norddeutschen Beckens. Geol Jb A131:99-116

Putnis A, Mauthe G (2000) The effect of pore size on cementation in porous rocks. Geofluids 1:37-41

Putnis A, Prieto M, Fernandez-Diaz L (1995) Supersaturation and crystallisation in porous media. Geol Mag 132:1-13

Rac MV, Chernyshev SN (1970) Klüftigkeit und Eigenschaften geklüfteter Gesteine (russ.), Moskau (Nedra)

Ruedrich J, Seidel M, Kirchner, Siegesmund S (2005) Salzverwitterung, hygrische und thermische Dehnung als auslösende Schadensquantitäten. In: Siegesmund S, Auras M, Rüdrich J, Snethlage R (eds) Geowissenschaften und Denkmalplfege ZDGG, vol 156/1, pp 59-74

Ruedrich J, Siegesmund S (2006) Fabric dependence of length change behaviour induced by ice crystallization in the pore space of natural building stones. In: Fort R, Alvarez de Buergo M, Gomez-Heras $\mathrm{M}$ et al (eds) Heritage, weathering and conservation. Taylor \& Francis Group, London

Rüdrich J, Bartelsen T, Dohrmann R, Siegesmund S (2010) Building sandstone integrity affected by the process of hygric expansion. Environ Earth Sci. doi:10.1007/s12665-010-0767-0

Ruedrich J, Bartelsen T, Dohrmann R, Siegesmund S (2011) Moisture expansion as a deterioration factor for sandstone used in buildings. Monument under threat. Environ Earth Sci 63:7-8

Scherer M (1987) Parameters influencing porosity in sandstones: a model for sandstone porosity prediction. Am Assoc Petroleum Geologists Bull 71(5):485-491

Scherer GW (1999) Crystallization in pores. Cem Conr Res 29:1347-1358

Schieß1 P, Alfes C (1990) Festigkeit und Verformung von Sandstein-Bedeutung für die Verwitterungsresistenz und Meßmethoden. Denkmalpflege und Naturwissenschaften im Gespräch, Sonderheft aus der Publikationsreihe des Verbundsforschungsprojekts Steinzerfall und Steinkonservierung:10-17, Berlin

Schmidt V, McDonald DA (2012) The role of secondary porosity in the course of sandstone diagenesis. In: Scholle PA, Schluger PR (eds) SEPM Society for Sedimentary Geology. Aspects of Diagenesis, vol 26, pp 175-207

Seidel G (2003) Geologie von Thüringen, Schweizerbart'sche Verlagsbuchhandlung, Stuttgart, 2. Aufl.

Seidel M (2004) Gefügeabhängige Verwitterung von Sandsteinen durch Kristallisation von Eis und Salzen im Porenraum un published diploma thesis, 159 pp, Göttingen
Siegesmund S, Dürrast H (2011) Physical and mechanical properties of rocks. In: Siegesmund S, Snethlage R (eds) Stone and architecture. Springer, Berlin, pp 97-225

Snethlage R, Wendler E (1997) Moisture cycles and sandstone degradation. In: Baer NS, Snethlage R (eds) Saving our architectural heritage, the conservation of historic stone structures. Elsevier, Hoboken, pp 7-24

Sobott R, Koch R (2009) Die Qualität von Naturwerksteinen aus dem Steinbruch Worzeldorf bei Nürnberg-Petrographische, diagenetische und gesteinsphysikalische Kenndaten (Mittlerer Keuper, Oberer Burgsandstein). Geol. B1. NO-Bayern, 59, pp 419-444, Erlangen

Stück H, Siegesmund Siegfried, Ruedrich J (2011) Weathering behaviour and construction suitability of dimension stones from the Drei Gleichen area (Thuringia, Germany). Environ Earth Sci 63:1763-1786. doi:10.1007/s12665-011-1043-7

Stonecipher SA, Winn RD Jr., Bishop MG (1984) Diagenesis of the Frontier Formation, Moxa Arch: a function of sandstone geometry, texture and composition, and fluid flux. In: McDonald DA, Surdam RC (eds) Clastic Diagenesis: AAPG Memoir 37, pp 289-316

Stalder PJ (1973) Influence of crystalline habit and aggregate structure of authigenic clay minerals on sandstone permeability. Geol Mijnbouw 52:217-219

Strack D, Stapf RG (1980) Ist der Kreuznacher Sandstein des Rotliegenden äolisch oder fluviatil entstanden? Geol Rundsch 69(3):892-921

Surdam RC, Dunn TL, MacGowan DB, Heasler HP (1989) Conceptual models for the prediction of porosity evolution with an example from the Frontier Sandstone, Big-Horn Basin, Wyoming. In: Coalson EB, Kaplan SS, Keighin CW, Oglesby LA, Robinson JW (eds) Sandstone Reservoirs: Rocky Mountain Association of Geologists, pp 7-21

Tukey J (1977) Exploratory data analysis. Addison-Wesley. ISBN 18750-201-07616-0

van Brakel J, Modry S, Svata M (1981) Mercury porosimetry: State of the art. Powder Technol 29:1-12

Van der Plas L, Tobi AC (1965) A chart of judging the reliability of point counting results. Am J Sci 263:87-90

Waples DW (2002) Evolution of sandstone porosity through time. The modified Scherer Model: a calculation method applicable to 1-D maturity modeling and perhaps to reservoir prediction. Nat Resour Res 11:257-272

Wenzel A, Häfner F (2003) Die roten Werksandsteine der Westpfalz.IFS Bericht Nr. 15-2003, p 27

Weiss T, Siegesmund S, Kirchner D, Sippel J (2004) Insolation weathering and hygric dilatation as a control in building stone degradation. Environ Geol 46(3-4):402-413

Wilson MD (1994) Non-compositional controls on diagenetic processes. In: Wilson MD (ed) Reservoir Quality Assessment and Prediction in Clastic Rocks: SEPM Short Course 30, pp 183-208

Worden R, Morad S (2000) Quartz cementation in sandstones. Special publication 29, International Association of Sedimentologists. Blackwell Science, Oxford

Wurster P (1964) Geologie des Schilfsandsteins. Mitt Geol Staatsinstituts Hamburg 33:1-140

Xiang W, Czurda K (1995) Einfluss des Kationenaustausches auf die Hydratation und Dehydratation von Tonmineralen. Festschrift zum 60. Geburtstag von Helfried Möller. Geol. Paläontologische Mitteilungen Innsbruck, Bd. 20:107-119

Tucker M (2001) Sedimentary petrology—revised. Blackwell Science Inc, Oxford

Zehnder K, Arnold A (1989) Crystal growth in salt efflorescence. J Crystal Growth 97:513-521 